\title{
Using LCZ data to run an urban energy balance model
}

\author{
Paul John Alexander ${ }^{\mathrm{a}, *}$, Gerald Mills ${ }^{\mathrm{b}}$, Rowan Fealy ${ }^{\mathrm{c}}$ \\ a Irish Climate Analysis \& Research Units (ICARUS), Maynooth University, Kildare, Ireland \\ ${ }^{\mathrm{b}}$ School of Geography Planning \& Environmental Policy (GPEP), University College Dublin, Belfield, Ireland \\ ${ }^{\mathrm{c}}$ Department of Geography, Maynooth University, Kildare, Ireland
}

\section{A R T I C L E I N F O}

\section{Article history:}

Received 17 June 2014

Revised 20 April 2015

Accepted 1 May 2015

\section{Keywords:}

LCZ

SUEWS

UEB

Urban

Landcover

\begin{abstract}
A B S T R A C T
In recent years a number of models have been developed that describe the urban surface and simulate its climatic effects. Their great advantage is that they can be applied in environments outside the cities in which they have been developed and evaluated. Thus, they may be applied to cities in the economically developing world, which are growing rapidly, and where the results of such models may have greatest impact with respect to informing planning decisions. However, data requirements, particularly for the more complex urban models, represent a major obstacle to their employment. Here, we examine the potential for running the Surface Urban Energy and Water Balance model (SUEWS) using readily obtained data. SUEWS was designed to simulate energy and water balance terms at a neighbourhood scale $\left(\geqslant 1 \mathrm{~km}^{2}\right)$ and requires site-specific meteorological data and a detailed description of the surface. Here, its simulations are evaluated by comparison with measurements made over a seven month (approximately 3 seasons) period (April-October) at two flux tower sites (representing urban and suburban landscapes) in Dublin, Ireland. However, the main purpose of this work is to test the performance of the model under 'ideal' and 'imperfect' circumstances in relation to the input data required to run SUEWS. The ideal case uses detailed urban land cover data and meteorological data from the tower sites. The imperfect cases use parameters derived from the Local Climate Zone (LCZ) classification scheme and meteorological data from a standard weather station located beyond the urban area. For the period of record examined, the simulations show good
\end{abstract}

* Corresponding author at: ICARUS Room 1.8 Laraghbryan House, North Campus, Maynooth University, Maynooth, Kildare, Ireland. Tel.: +353 17083432 .

E-mail address: paul.alexander@nuim.ie (P.J. Alexander). 
agreement with the observations in both ideal and imperfect cases, suggesting that the model can be used with data that is more easily derived. The comparison also shows the importance of including vegetative cover and of the initial moisture state in simulating the urban energy budget.

(c) 2015 Elsevier B.V. All rights reserved.

\section{Introduction}

Within the next four decades the global population is projected to increase by 2.3 billion, within the same period it is expected that urban areas will gain 2.6 billion (UN, 2012), absorbing projected growth and continuing to draw from existing rural populations. While this trend appears globally, there are regional differences. The urban population in more economically developed regions has already reached $78 \%$, whereas in less developed regions it currently stands at $47 \%$. Taking the projections for Asia and Africa together, their urban population will grow by 2.3 billion by the middle of the century. If these projections are realised, most of the urbanisation in the future will occur in the economically developing world (Satterthwaite, 2007). Responding to this challenge will result in large-scale housing and critical infrastructure projects (e.g. energy and water supply, waste removal facilities and transport) that, once in place, create an urban form that is difficult to change; hence, it is important that urban growth is well managed. At least two responses might be expected: horizontal expansion of the urban area and densification of the existing urban fabric (Moonen et al., 2012). If future urban development is to reduce environmental impacts (e.g. air quality, hydrology and thermal effects) that result from conventional urbanisation some guidance on development pathways is needed (Schwela, 2000; Schuster et al., 2005; Arnfield, 2003; Chen and Ng, 2012). One component of this guidance should be physically-based models that can simulate the effect of alternative urban plans and designs and inform decision-making. However, these models only have value if they have been tested, that is, applied to urban places, evaluated against observations and validated. Unfortunately, there are few examples of the application of urban climate models to these types of problems (Oke, 2006).

Although there are an increasing number of diverse urban climate models available, there is little evidence that they are routinely applied. A significant impediment to their route use includes the paucity of relevant information on: the physical character of cities (that is the buildings, materials, layout, etc.) needed to derive model parameters and; the meteorological data needed to 'force' the models and evaluate their simulations. In fact, the lack of urban specific data has been recently highlighted in the 5th assessment report (AR5) of the Intergovernmental Panel on Climate Change (IPCC, 2014). Specifically AR5 highlights serious data limitations with respect to geophysical, biological and socio-economic data, as well as inadequate knowledge surrounding the vulnerability of the built environment and building materials to climate change. These issues are particularly acute for the rapidly growing cities of the economically developing world, many of which are outside the mid-latitude climates where the models have been developed and may lack the necessary urban and meteorological information required. Recently, a protocol for collecting urban parameters in an efficient and standardised manner has been proposed to address this problem (Ching, 2013; Bechtel et al., 2015).

This paper examines the issue of information quality and its impact on the performance of an urban energy balance model (UEB). The Surface Urban Energy and Water Balance model (SUEWS) is a moderately complex UEB that requires detailed information on the urban landscape and is usually run using on-site meteorological data. We use SUEWS to simulate the energy budget at two Dublin locations for which we have detailed energy flux stations and detailed spatial information (e.g. individual building footprints, heights) on the surrounding urban landscape. This allows us to run the model and evaluate its simulations of turbulent fluxes over a period of time. We then use readily available standard meteorological data and coarse land-cover data and perform the same evaluation. The 
performance of SUEWS is judged against two different urban landscapes - city centre and green suburbs - where eddy-flux towers are located that provide observations of the UEB terms. The results are compared with observations to assess the relative effect of input data quality. Specifically we address two questions, which have implications for the use of UEB models in data-poor settings:

1. How does SUEWS perform in terms of discriminating between different urban environments when run using readily available but coarse land-cover data and standard meteorological data relative to using optimal data?

2. Specific to the Dublin case study, which is more important for running SUEWS; on-site detailed meteorological data or high quality, spatially detailed land-cover?

The answers are based on the application of the SUEWS in Dublin (Ireland), for which we have a range of data suitable for evaluating model performance under ideal and non-ideal circumstances.

\section{Urban energy budget (UEB) models}

A number of urban models have been developed at a variety of spatial and temporal scales with a range of applications, the most common of which are based on the surface energy budget (Oke, 1988),

$$
Q^{*}+Q_{F}=Q_{H}+Q_{E}+\Delta Q_{S}, \quad\left[\mathrm{~W} \mathrm{~m}^{-2}\right]
$$

where $Q^{*}$ is net radiation, $Q_{F}$ is anthropogenic heat flux, $Q_{H}$ and $Q_{E}$ are the turbulent sensible and latent heat fluxes respectively and $\Delta Q_{S}$ is storage heat flux. This equation refers to a representative urban volume that extends from of the surface in which there is no net horizontal transfer (that is, an extensive surface type) and no significant energy exchange across the lower boundary. Hence, assessing each of the terms at the upper surface of the volume, which is located above the canopy layer captures the exchanges between the urban surface and overlying boundary layer. The process of urbanisation results in the replacement of natural surfaces by hard impervious surfaces (e.g. roads, pavements, car parks) and buildings. This greatly alters the surface energy balance by, for example, increasing (decreasing) the sensible (latent) heat flux and increasing heat storage. One of the best known outcomes is the formation of an urban heat island (Oke, 1980; Grimmond and Oke, 2002).

There are three approaches for UEB modelling: deriving empirically based models; modification of existing models designed for non-urban areas and; development of new models with urban specific conceptualisation and physics (Hidalgo et al., 2008). The latter two approaches simulate the urban effect by describing the urban landscape using parameterisations that can range from the very simple e.g. concrete slab approach used by Taha (1999) and Kusaka and Kimura (2004) to more complex schemes that take into account building dimensions, materials, and internal energy use, see for example, Kimura and Takahashi (1991), Mills (1997), Masson (2000), Martilli et al. (2002) and Kanda et al. (2005). Most of these describe urban areas by partitioning the surface into cells each of which has distinct properties related to aspects of urban form (e.g. fraction that is impervious) and function (e.g. anthropogenic heat flux). Evaluating and comparing these models has proved difficult owing to their distinct histories, which reflects different designs that have evolved in response to user needs and data requirements and availability. In fact, there has been a call for the standardisation of how parameters are gathered regardless of which model is being employed (Ching, 2013; Bechtel et al., 2015). This would greatly aid communication among researchers, allow for better comparisons between models and allow the transfer of models (and results) between cities.

Grimmond et al. (2010 and 2011) categorised 33 UEB models into simple, medium and complex based on 12 characteristics and compared their simulations against observations of the UEB made across a range of urban settings (see Table 1). In these tests, each UEB model had distinct merits such that no single model performed best or worst in comparisons; however broad conclusions emerged. First, those models that included information on building facades (that is the walls and roof) and on vegetation had smaller errors when simulating outgoing shortwave radiation $(K \uparrow)$, net radiation $\left(Q^{*}\right)$ and the turbulent fluxes $\left(Q_{H}\right.$ and $\left.Q_{E}\right)$. Second, providing additional data on building materials (such as detailed thermal properties and albedo) did not necessarily improve the models performance; 
Table 1

Aspects of UEB models which are used for classification of model complexity. For example in the case of criteria 1, "simple" would be associated with modelling only one or two fluxes, "complex" would be associated with modelling all fluxes.

\begin{tabular}{rlll}
\hline Criteria & Characteristic & Typical treatment (Categories) & Levels of complexity \\
\hline 1 & Fluxes included & All fluxes/individual fluxes & 4 \\
2 & Vegetation & Separated/integrated & 3 \\
3 & $Q_{F}$ & Internal building/modelled & 4 \\
4 & Temporal $\Delta Q_{S}$ & Fixed/variable & 3 \\
5 & Urban morphology & Single layer(s)/multiple & 7 \\
6 & Facet/orientation & Bulk/canyons & 4 \\
7 & Reflections & Single/multiple/infinite & 3 \\
8 & Albedo/emissivity & Bulk/multiple facets & 3 \\
9 & $\Delta Q_{S}$ & Residual/conduction & 3 \\
10 & Resistance & Single layer/multi-layer & 3 \\
11 & Surface temperature/moisture & Bulk/single/multiple & 4 \\
12 & Air temperature/moisture & Forcing height/single/multi-layer & 3 \\
\hline
\end{tabular}

for simple models, a net improvement was often observed but this was not the case for complex models. In other work, Loridan et al. (2010) evaluated the single-layer urban climate model (SLUCM), as a component of the mesoscale Weather Forecasting Model (WRF) model, and found that data on vegetative cover was especially important for improved simulations. Similarly, Loridan and Grimmond (2012) using the same model found that using data that described the character of urban neighbourhoods where flux observations are made, rather than using generic urban data, had a marked effect; SLUCM was better able to reproduce the turbulent fluxes at 15 sites across the US, Mexico, Canada, Australia, Finland and Poland.

These studies provide a cautionary tale; while information on the nature of the urban surface is critical for UEB simulations, there is no guarantee that acquiring more detailed information will improve model performance. This has significant implications for the acquisition of urban data suited for a model as it can take a considerable amount of time but might yield little benefit. For example, UEB model evaluations consistently show the value of information on vegetation for simulating the turbulent fluxes but this does not mean that obtaining information on the details of trees (e.g. species, age, health, etc.) will make a difference to simulations. This is important as, from a planning and design perspective, city greening initiatives are a major component of climate-based policies and any UEB model chosen must be able to assess the impact of modifying vegetation cover/type (Breuste, 2004; Kovács and Németh, 2012). However, it will be important to know what sort of data is needed, as this will guide the type of modelling exercise and help in interpreting the results. Practically then the challenge is to acquire urban data at a sufficient scale and detail to run a validated model suited for a purpose.

For many purposes, it may be possible that model 'look-up' tables that link urban landscape types to typical climate-relevant parameters could address the lack of land-cover information. The Local Climate Zone (LCZ) classification scheme for example, partitions the landscape into 10 urban and 7 non-urban classes, permits mixed categories and allows seasonality to be taken into account (see Table 2; Stewart and Oke, 2012). The advantages of this approach include: LCZ types are purported to be universal in their depiction of landscapes and their climate impacts; it is relatively easy to categorise urban neighbourhoods into an LCZ type from fieldwork and readily available sources (e.g. GoogleEarth) and; each LCZ type is associated with a typical range of parameter values that describe surface cover, building heights and street aspect ratio, etc. (Table 2). The scheme has been applied most to the study of the Urban Heat Island (UHI), for which it was developed - see Fenner et al. (2014), Leconte et al. (2014), and Stewart et al. (2014). As an example, Fig. 1 shows the LCZ map of Dublin, which was generated for an urban heat island study using available land-cover data, remote sensing and fieldwork (Alexander and Mills, 2014).

\section{Methodology}

In this work we examine the quality of the input data needed to run a moderately complex UEB model satisfactorily. Our examination is based on data gathered for Dublin, Ireland $\left(53^{\circ} \mathrm{N}, 6^{\circ} \mathrm{W}\right)$, which 


\section{Table 2}

Outline of Local Climate Zone Classes and their properties (modified from Stewart and Oke, 2012). Those that are asterisked are present in the Dublin study area.

\begin{tabular}{lllll}
\hline $\begin{array}{l}\text { Local Climate } \\
\text { Zone (LCZ) }\end{array}$ & $\begin{array}{l}\text { Building surface } \\
\text { fraction (\%) }\end{array}$ & $\begin{array}{l}\text { Impervious surface } \\
\text { fraction }\end{array}$ & $\begin{array}{l}\text { Pervious surface } \\
\text { fraction }\end{array}$ & $\begin{array}{l}\text { Height of roughness } \\
\text { elements (m) }\end{array}$ \\
\hline Compact high-rise & $40-60$ & $40-60$ & $<10$ & $>25$ \\
${ }^{*}$ Compact midrise & $40-70$ & $30-50$ & $<20$ & $10-25$ \\
${ }^{*}$ Compact low-rise & $40-70$ & $20-50$ & $<30$ & $3-10$ \\
Open high-rise & $20-40$ & $30-40$ & $30-40$ & $>25$ \\
${ }^{*}$ Open midrise & $20-40$ & $30-50$ & $20-40$ & $10-25$ \\
${ }^{*}$ Open low-rise & $20-40$ & $20-50$ & $30-60$ & $3-10$ \\
Lightweight low-rise & $60-90$ & $<20$ & $<30$ & $2-4$ \\
${ }^{*}$ Large low-rise & $30-50$ & $40-50$ & $<20$ & $3-10$ \\
Sparsely built & $10-20$ & $<20$ & $60-80$ & $3-10$ \\
${ }^{*}$ Heavy industry & $20-30$ & $20-40$ & $40-50$ & $5-15$ \\
${ }^{*}$ Dense trees & $<10$ & $<10$ & $>90$ & $3-30$ \\
Scattered trees & $<10$ & $<10$ & $>90$ & $3-15$ \\
Bush, scrub & $<10$ & $<10$ & $>90$ & $<2$ \\
${ }^{*}$ Low plants & $<10$ & $>10$ & $>90$ & $<1$ \\
${ }^{*}$ Bare rock or paved & $<10$ & $<10$ & $<10$ & $<0.25$ \\
Bare soil or sand & $<10$ & $<10$ & $>90$ & $<0.25$ \\
${ }^{*}$ Water & $<10$ & & $>90$ & - \\
\hline
\end{tabular}

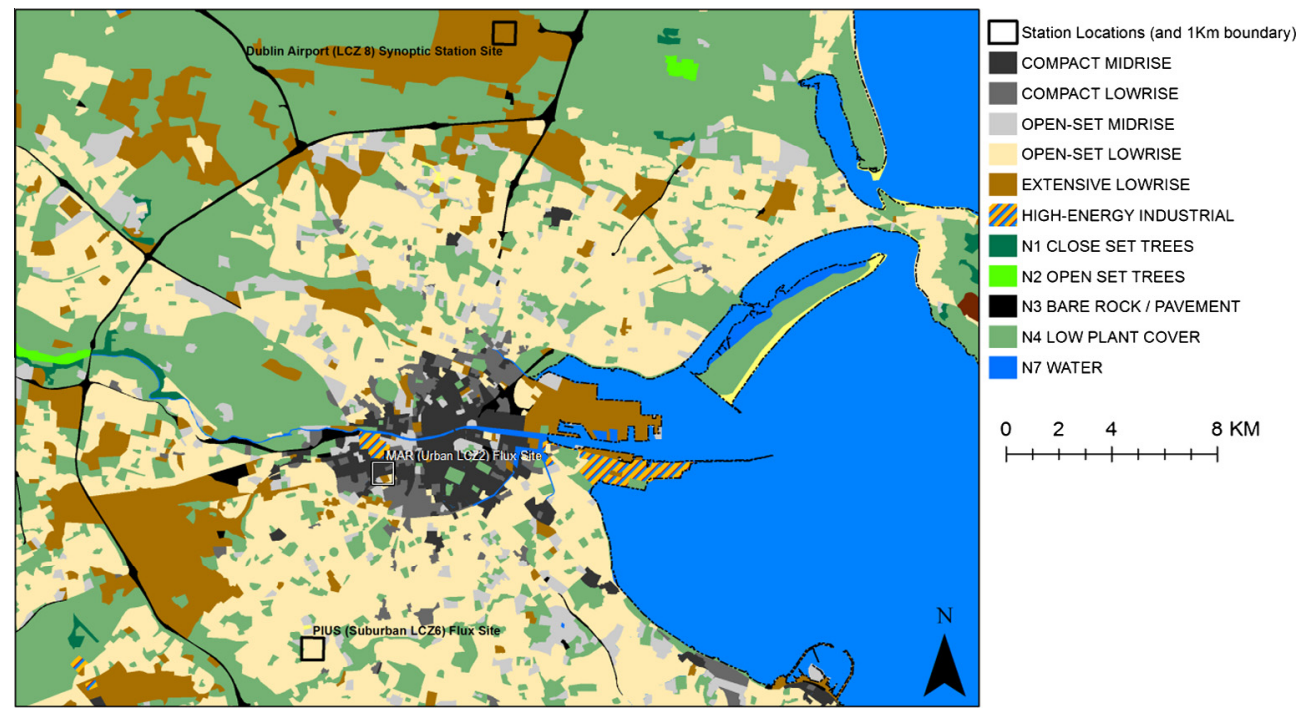

Fig. 1. LCZ map of Dublin. Also shown are flux site locations and synoptic station location with a $1 \mathrm{~km}$ grid box which represents extent of area used to calculate surface fractions (Modified from Alexander and Mills, 2014).

has a mild, mid-latitude climate ( $\mathrm{Cfb}$ ). It provides an ideal place for this study as it has two observation sites (located in urban and suburban neighbourhoods) where detailed energy flux and meteorological observations have been made since 2009; these data can be used to run the model and compare its simulations with observations. In addition: there is a LCZ description of the city that outlines major neighbourhood types and; a WMO standard weather station at Dublin Airport, which is $5-10$ km distant from the flux sites, records hourly observations.

The Surface Urban Energy and Water balance Scheme (SUEWS v.2013b) is used to simulate the UEB (Eq. (1)) of both neighbourhoods. SUEWS requires a relatively low number of input parameters that may include: meteorological data; socio-economic-demographic data and; surface cover and urban 
structure data. Some of these inputs are required to run the model, while other inputs are optional. At the very least the model requires standard meteorological data and details on the fractions of the landscape that is occupied by buildings, vegetation, impervious paving, etc. The challenges of operational employment of the earlier stages of model have been documented (Cleugh et al., 2005) and include the parameterisation schemes themselves along with acquiring the necessary forcing data.

Järvi et al. (2011) evaluated SUEWS using flux observations (spanning various time lengths from different years) from sites in Los Angeles ( $34^{\circ} \mathrm{N}$, Köppen climate type, Csb) and Vancouver ( $49^{\circ} \mathrm{N}$, $\mathrm{Cfb}$ ). The results showed the model to be capable of simulating net radiation, sensible and latent and heat fluxes with RMSE ranges of $25-47 \mathrm{~W} \mathrm{~m}^{-2}, 30-64 \mathrm{~W} \mathrm{~m}^{-2}$ and $20-56 \mathrm{~W} \mathrm{~m}^{-2}$, respectively. Moreover, while the model reproduced the diurnal cycle of the turbulent fluxes, it tends to underestimate $Q_{E}$ and overestimate $Q_{H}$ in the day time. Here, we compare SUEWS model output with energy flux observations at two flux sites. The initial model runs use detailed site-specific meteorological and land-cover data. Subsequently, SUEWS is run using meteorological data from Dublin Airport and land-cover data representative of the LCZ type in which each flux site is located. In the following sections we describe the SUEWS model, the meteorological/flux data and the urban land-cover data used in this study. We then outline the structure of the experiment.

\subsection{SUEWS}

SUEWS was designed for urban simulations at a neighbourhood-scale, which corresponds to an area of approximately $1 \mathrm{~km}^{2}$. It simulates both the urban energy budget (Eq. (1)) and water budget (Grimmond and Oke, 1991),

$$
P+I_{e}+F=E+R+\Delta S \quad\left[\mathrm{~mm} \mathrm{~h}^{-1}\right]
$$

where $P$ is precipitation, $I_{e}$ is externally piped water, $F$ is anthropogenic water emission, $E$ is evaporation (including transpiration), $R$ is runoff and $\Delta S$ is change in storage. Eqs. (1) and (2) are connected directly through the evaporative terms $\left(Q_{E}\right.$ and $\left.E\right)$ and indirectly via other terms; for example a precipitation event may result in water storage in soil that will affect its thermal properties. The energy budget (Eq. (1)), which is the focus of this paper describes flux exchanges at a plane that separates the roughness sub-layer (between 2 and 4 times the mean height of the roughness elements) from the remainder of the boundary-layer. The modelled fluxes therefore correspond to the inertial sub-layer, where micro-scale variability driven by individual roughness elements becomes integrated into neighbourhood signals. Moreover, one should note the absence of advective terms in Eq. (1), so that it assumes there is a negligible horizontal energy transfer. Strictly speaking then, this limits the application of SUEWS to extensive neighbourhood types where the landscape may be described as relatively homogenous (Middel et al., 2012). The absence of detailed accounting for radiative transfer within the canyons below the simulated level should also be noted.

The data inputs employed by the model are listed in Table 3 and include hourly meteorological data, land cover parameters and anthropogenic fluxes. SUEWS describes the milieu of different surface types in a neighbourhood in terms of fractional coverage $(\lambda)$ of buildings, pavements, water, vegetated areas (both irrigated and non-irrigated) and trees (coniferous and deciduous) and unmanaged land cover such as bare soils or rock. Anthropogenic water and energy use can also be provided; hourly water use can be expressed as a proportion of the daily total and hourly anthropogenic heat fluxes can be estimated from typical daily patterns, divided into weekday and weekend values.

\subsection{Meteorological and energy flux data}

The atmospheric observations used here are of two types. The first is standard meteorological information obtained from Dublin Airport, which is located $5 \mathrm{~km}$ from the city centre in an area dominated by warehouses (Fig. 1). Hourly observations are available for a number of elements: air temperature $(T)$, precipitation $(P)$, pressure $(\operatorname{Pr})$, humidity $(\mathrm{RH})$, wind-speed $(V)$ and direction and solar radiation received $(K \downarrow)$. Note that hourly values for $K \downarrow$ are a required model input.

The second is meteorological and energy flux data that is acquired at two stations (Fig. 1) that are part of the International Urban Flux Network (Keogh et al., 2012). The measurement sites were 
Table 3

Summary of inputs required to run SUEWS model.

\begin{tabular}{|c|c|c|}
\hline Variable & Units & Comments \\
\hline $\begin{array}{l}\text { Meteorological } \\
\text { Air temperature }(T) \\
\text { Relative humidity (RH) } \\
\text { Pressure (Pr) } \\
\text { Precipitation }(P) \\
\text { Wind speed }(V) \\
\text { Incoming short wave }(K \downarrow) \\
\text { Incoming long wave }(L \downarrow) \\
\text { Observed sensible heat }\left(Q_{H}\right) \\
\text { Observed latent heat }\left(Q_{E}\right) \\
\text { Observed storage heat }\left(\Delta Q_{S}\right) \\
\text { Cloud fraction } \\
\text { Soil moisture deficit } \\
\text { Leaf Area Index (LAI) }\end{array}$ & $\begin{array}{l}{ }^{\circ} \mathrm{C} \\
\% \\
\mathrm{kPa} \\
\mathrm{mm} \mathrm{h}^{-1} \\
\mathrm{~m} \mathrm{~s}^{-1} \\
\mathrm{~W} \mathrm{~m}^{-2} \\
\mathrm{~W} \mathrm{m^{-2 }} \\
\mathrm{W} \mathrm{m^{-2 }} \\
\mathrm{W} \mathrm{m^{-2 }} \\
\mathrm{W} \mathrm{m}^{-2} \\
\text { Tenths } \\
\mathrm{m}^{3} \mathrm{~m}^{-3}\end{array}$ & $\begin{array}{l}\text { Optional (otherwise uses } T \text { and } \mathrm{RH} \text { ) } \\
\text { Optional } \\
\text { Optional } \\
\text { Optional } \\
\text { Optional } \\
\text { Optional } \\
\text { Optional }\end{array}$ \\
\hline $\begin{array}{l}\text { Anthropogenic inputs } \\
\text { Anthropogenic heat }\left(Q_{F}\right) \\
\text { Anthropogenic water use }\end{array}$ & $\begin{array}{l}\mathrm{W} \mathrm{m}^{-2} \\
\%\end{array}$ & $\begin{array}{l}\text { Optional, hourly values (otherwise modelled) } \\
\text { Optional, hourly ratio of total diurnal usage }\end{array}$ \\
\hline $\begin{array}{l}\text { Surface inputs } \\
\text { Fractional coverage of surface types }(\lambda)\end{array}$ & $\%$ & $\begin{array}{l}\text { Urban, pavement, soil, grass (irrigated and un-irrigated), } \\
\text { trees (coniferous and deciduous) water }\end{array}$ \\
\hline $\begin{array}{l}\text { Surface area } \\
\text { Water usage area } \\
\text { Latitude/longitude }\end{array}$ & $\begin{array}{l}\mathrm{Ha} \\
\mathrm{Ha} \\
\circ\end{array}$ & Optional \\
\hline $\begin{array}{l}\text { Storage capacity of pipes } \\
\text { Frontal area fractions }\end{array}$ & $\mathrm{mm}$ & $\begin{array}{l}\text { Optional } \\
\text { Optional, buildings and trees separate }\end{array}$ \\
\hline $\begin{array}{l}\text { Roughness length for momentum }\left(z_{0}\right) \\
\text { Zero displacement height }\left(z_{d}\right) \\
\text { Surface element heights }\end{array}$ & $\begin{array}{l}\mathrm{m} \\
\mathrm{m} \\
\mathrm{m}\end{array}$ & $\begin{array}{l}\text { Optional } \\
\text { Optional } \\
\text { Optional, buildings and trees separate }\end{array}$ \\
\hline
\end{tabular}

Table 4

A list of the energy budget and meteorological variables and the instruments used at each site; the height of the instruments at urban and suburban sites respectively is shown in the parentheses. The final column lists the equivalent SUEWS parameters (Table 3).

\begin{tabular}{lll}
\hline Variable & Instrument & SUEWS parameter \\
\hline Radiation & Net radiation sensor (15/11) & $K \downarrow, K \uparrow, L \downarrow, L \uparrow$ \\
3D wind velocity & Hukseflux (NR01) & $V, Q_{H}, Q_{E}$ \\
Water vapour density & Sonic anemometer (17/12) & $Q_{E}$ \\
Air temperature and relative humidity & Campbell Scientific (CSAT3) & Temperature and relative humidity probe (17/12) \\
& InfraRed Gas Analyser (17/12) \\
Precipitation & Vaisala HMP45C & $P$ \\
\hline
\end{tabular}

selected to represent sites that typify Dublin's urban land-cover. Each has an identical suite of instruments (see Table 4) and radiation and turbulent flux terms are recorded alongside the meteorological variables listed above. The suburban site is located in a residential area consisting of similar two-story houses about $6 \mathrm{~m}$ tall and much of the landcover is vegetated (open low-rise or LCZ6). The instruments are positioned on a mast that is located on the roof of a school at a height of $12 \mathrm{~m} \mathrm{(10} \mathrm{m} \mathrm{for} \mathrm{the} \mathrm{net}$ radiometer). The urban site is located in a mixed-use area closer to the city centre; much of the surrounding landscape is impermeable and the average building height is about $8 \mathrm{~m}$ (compact midrise or LCZ2). The support mast is on the roof of a $12 \mathrm{~m}$ tall building and the instruments are at a height of $17 \mathrm{~m}$ ( $15 \mathrm{~m}$ for net radiometer). 
Upward and downward facing radiometers provide $K \downarrow, K \uparrow, L \downarrow$ and $L \uparrow$. The turbulent fluxes $Q_{H}$ and $Q_{E}$ heat are obtained using an open-path eddy covariance system that is interrogated at a rate of $10 \mathrm{~Hz}$; the recorded fluxes are based on 30 min averages. These data are then corrected following Webb et al. (1980), which results in increasing $Q_{E}$ and decreasing $Q_{H}$ and somewhat reducing the residual. The heat storage term $\left(\Delta Q_{S}\right)$ is then estimated as a residual of the measured terms,

$$
\Delta Q_{S} \approx Q^{*}-\left(Q_{H}+Q_{E}\right)\left[\mathrm{W} \mathrm{m}^{-2}\right]
$$

Thus, $\Delta Q_{S}$ includes any errors associated with the estimation of the other fluxes. Also, while the anthropogenic heat flux $\left(Q_{F}\right)$ is not distinguishable in the observations, it is present in all the measured terms.

Each tower is located well within its LCZ type and the flux instruments are positioned at a level that is approximately twice the height of the surrounding buildings and at about the height of the inertial sub-layer established by that surface type. In other words, we are assuming that advection is negligible and that $\Delta Q_{A}$ can be ignored. Finally, it is also assumed that the makeup of source regions for the radiation $(K \uparrow$ and $L \uparrow)$ and the turbulent $\left(Q_{H}\right.$ and $\left.Q_{E}\right)$ fluxes are similar even though the source for the former is fixed and that for the latter changes with wind direction and stability (Oke, 2006). In practice, this means that observations of $K \uparrow$ and $L \uparrow$ are strongly dependent on the surfaces directly below the sensors. In the case of the suburban site, which is a located in the grounds of a small school, the underlying surface consists mostly of a dark roof surface and asphalt car park so that these terms are less likely to be representative of the open low-rise suburban setting than the turbulent terms.

For both data types, observations for the period April 08 - October 182010 were used. Both the winter period 2009 (i.e. November 2009 - January 2010) and 2010 (November 2010 - January 2011) saw atypical synoptic conditions, specifically widespread snow/ice was present across both Ireland and the UK for most of the period. This resulted in restricted access to on-site data loggers at the flux locations. As such, the period of observations utilised represents a contiguous period of observations without significant data gaps.

\subsection{Urban land-cover parameters}

The required urban land-cover fractions ( $\lambda$, see Table 5 ) were derived using GoogleEarth. Values of $\lambda$ were calculated for a $1 \mathrm{~km}^{2}$ area around each flux site by digitizing polygons representing roads, buildings and vegetated surfaces and points to represent trees. The total tree canopy coverage was estimated based on the average canopy size for trees in Dublin (Ningal et al., 2010). All trees were classified as deciduous. The total area coverages of buildings, pavements, water, vegetated areas, trees and unmanaged land were computed and then converted to fraction values $(\lambda)$ for each site.

\section{Table 5}

Local Climate Zones (LCZ) in Dublin city with estimated plan area fractions $(\lambda)$. These were computed by taking the average of $n$ randomly sampled areas $\left(1 \mathrm{~km}^{2}\right.$ in size) within each LCZ type. The equivalent fractions calculated for the area around the urban and suburban observation sites are listed in the final two rows.

\begin{tabular}{|c|c|c|c|c|c|c|c|}
\hline LCZ & Built & Impervious & Unmanaged & Trees & Grass & Water & $(n)$ \\
\hline 2 Compact mid & 33 & 55 & 00 & 06 & 06 & 00 & 5 \\
\hline 3 Compact low & 22 & 61 & 00 & 07 & 10 & 00 & 5 \\
\hline 5 Open mid & 13 & 48 & 00 & 11 & 28 & 00 & 5 \\
\hline 6 Open low & 14 & 52 & 00 & 11 & 23 & 00 & 10 \\
\hline 8 Large low & 30 & 61 & 00 & 04 & 05 & 00 & 5 \\
\hline 10 Industrial & 16 & 69 & 00 & 08 & 07 & 00 & 5 \\
\hline 101 Close trees & 01 & 02 & 04 & 48 & 45 & 00 & 5 \\
\hline 104 Low plant & 03 & 08 & 03 & 18 & 67 & 00 & 10 \\
\hline 105 Bare rock & 09 & 49 & 00 & 14 & 29 & 00 & 2 \\
\hline 106 Bare sand & 06 & 20 & 55 & 19 & 00 & 00 & 1 \\
\hline 107 Water & 00 & 00 & 00 & 00 & 00 & 100 & - \\
\hline Urban site (LCZ2) & 33 & 66 & 00 & 00 & 00 & 00 & - \\
\hline Suburban site (LCZ6) & 18 & 48 & 00 & 05 & 29 & 00 & - \\
\hline
\end{tabular}


The LCZ scheme also provides a range of $\lambda$ values for each of the 17 types (Table 2) and for the Dublin study area, 11 of these types are present (Fig. 1). Fractional areas were calculated using GIS for each of these by random sampling from within each type; the size of sample varied in proportion to the area that that LCZ type occupied in the city (Grimmond and Souch, 1994). Thus for example, we sampled at 10 locations within the large suburban swath around the city centre (Open low-rise type, LCZ6) and at 5 places in the more densely built city centre (Compact mid-rise, LCZ2). None of the sampled places correspond with the observation site calculations. We treated the LCZ impervious fraction as pavement surface type in SUEWS. The final $\lambda$ values calculated for each LCZ is the average of the sampled sites (Table 5); a comparison with the LCZ ranges is presented in Table 2.

\subsection{Model experiment}

SUEWS is run in four modes, which are used to represent optimal and suboptimal modes:

\begin{tabular}{|c|c|c|c|c|}
\hline Mode & Land cover & Meteorological forcing & Description & Pairing \\
\hline 1 & High-resolution & Flux sites & $\begin{array}{l}\text { Optimal situation that } \\
\text { uses meteorological } \\
\text { data and land-cover } \\
\text { parameters for the } \\
\text { observation sites }\end{array}$ & Modes 2 and 4 \\
\hline 2 & High-resolution & $\begin{array}{l}\text { Off-site standard } \\
\text { weather station }\end{array}$ & $\begin{array}{l}\text { Suboptimal as it uses } \\
\text { meteorological data } \\
\text { from a standard } \\
\text { weather station to } \\
\text { represent the city }\end{array}$ & Modes 1 and 3 \\
\hline 3 & $\mathrm{LCZ}$ & $\begin{array}{l}\text { Off-site standard } \\
\text { weather station }\end{array}$ & $\begin{array}{l}\text { Suboptimal as it uses } \\
\text { meteorological data } \\
\text { from a standard } \\
\text { weather station and } \\
\text { land-cover parameters } \\
\text { estimated for the } \\
\text { larger LCZ } \\
\text { neighbourhood type } \\
\text { in which the sites are } \\
\text { situated }\end{array}$ & Modes 4 and 2 \\
\hline 4 & $\mathrm{LCZ}$ & Flux sites & $\begin{array}{l}\text { Suboptimal as it uses } \\
\text { LCZ land cover } \\
\text { parameters and } L \downarrow \text { is } \\
\text { derived from } T \text { and RH } \\
\text { (Loridan et al., 2011) }\end{array}$ & Modes 3 and 1 \\
\hline
\end{tabular}

Simulations were completed for the period April 08 - October 182010 (that is, Julian dates 98 through 291 ), which corresponds with the period for which daily observations of $Q^{*}, Q_{H}, Q_{E}$ and $\Delta Q_{S}$ are available for both flux sites. Our comparison between different Modes is based on the hourly values and on the average diurnal (daily) profiles calculated for each month. The anthropogenic heat and water fluxes options in SUEWS are not implemented here; this is reasonable in the Irish climate which is mild and wet and the contributions of traffic is likely to be small (perhaps $\leqslant 20 \mathrm{~W} \mathrm{~m}^{-2}$ using Pigeon et al. (2007) as a guide).

At the start of the period (April) the soil moisture status in SUEWS is set at field capacity (150 mm). The recorded precipitation at stations around Dublin in March, 2010 was about $55 \mathrm{~mm}$ which represented $110 \%$ of the average for that month and resulted in wide spread localised flooding toward the end of the month. At agricultural meteorological stations proximate to Dublin, soil moisture deficit 
(SMD) was reported at $-10 \mathrm{~mm}$ (surplus) at stations. The spring period (February-April) of 2010 was especially cold so it might be expected that vegetation growth was inhibited, even in the city. To account for this, the Leaf Area Index (LAI) at the beginning of April was obtained from MODerate Resolution Imaging Spectroradiometer (MODIS) data (MOD-15), which are available at $1 \mathrm{~km}^{2}$ resolution at 8-day intervals.

\subsection{Model evaluation and sensitivity}

The performance of SUEWS run in each of the Modes listed above is evaluated against the observations at the urban and suburban flux sites. A measure of the goodness of fit for each modelled term is provided by the RMSE,

$$
\text { RMSE }=\left[\sum_{i=1}^{n} \frac{\left(\hat{y}_{i}-y_{i}\right)^{2}}{n}\right]^{0.5}
$$

where $\left(\hat{y}_{i}-y_{i}\right)$ represents the difference between the observed $(y)$ and simulated $(\hat{y})$ flux term (e.g. $\left.Q^{*}\right)$ at each hourly time interval $(i) ; N$ represents the total number of hours. RMSE is commonly used to assess the total error, regardless of its direction. To measure any bias in the simulations the Mean Fractional Bias (MFB) is used,

$$
\mathrm{MFB}=\frac{1}{n} \sum_{i=1}^{n} \frac{\left(\hat{y}_{i}-y_{i}\right)}{\left(\hat{y}_{i}+y_{i}\right) / 2}
$$

where all terms have the same meaning as in the RMSE; this statistic produces a value between -2 and +2 where the sign indicates over $(+)$ or under $(-)$ estimates. Additionally, to examine the relative performance across all months between each Mode we generated Taylor diagrams for each of the simulated flux terms which employ three statistics: the centred RMSE $\left(E^{\prime}\right)$, the correlation coefficient $(R)$, and the standard deviation $(\sigma)$ (Taylor, 2001):

$$
\begin{aligned}
& E^{\prime}=\frac{1}{N} \sum_{i=1}^{N}\left[\left(\hat{y}_{i}-\overline{\hat{y}_{i}}\right)-\left(y_{i}-\overline{y_{i}}\right)\right]^{2} \\
& R=\frac{\frac{1}{N} \sum_{i=1}^{N}\left(\hat{y}_{i}-\overline{\hat{y}_{i}}\right)\left(y_{i}-\hat{y}\right)}{\sigma_{\hat{y}} \sigma_{y}}
\end{aligned}
$$

where $\sigma_{\hat{y}}$ and $\sigma_{y}$ are the standard deviations of the model and observed variable, respectively. The other terms are the same as Eq. (4) and resulting values are in $\mathrm{W} \mathrm{m}^{-2}$ with the exception of Eqs. (5) and (7). For the period of examination, there are a total 4656 hourly values (194 days) of observed $(y)$ and simulated $(\hat{y})$ values for each model run for each site.

To test the sensitivity of SUEWS to differences in meteorological forcing data (for example differences which might arise between off-site and on-site stations) we employed a one-factor-a-time (OFAT) approach (Griensven et al., 2002). First, we generated highly typified data i.e. data derived from a loess curve for a $168 \mathrm{~h}$ period for each required meteorological variable (see Table 3 ). We excluded precipitation from these data. To test SUEWS sensitivity to $K \downarrow, T / R H$ and $V$ we perturbed these data $\pm 10 \%$ of the mean state in order to examine the impact on modelled turbulent fluxes $\left(\Delta Q_{S}, Q_{H}\right.$ and $Q_{E}$ ). For the purpose of our OFAT analysis we distributed land cover evenly across all land cover types (excluding water), meaning differences in our simulations of $\Delta Q_{S}, Q_{H}$ and $Q_{E}$ between each perturbation would arise due to the modification of forcing data.

\section{Results}

In the following section the relative performance of SUEWS in each Mode is examined by comparing simulated and observed fluxes at each site. Initially, the diurnal performance of SUEWS when run in different Modes is examined based on the hourly simulations for the month of June. In this section 
we also present the differences between our forcing data sites. Subsequently, the overall performance of the model based on daily outcomes is presented followed by an examination of the impact of modifying: the land cover and meteorological forcing data.

\subsection{Hourly fluxes comparison - June 2010}

The meteorological forcing data available for the Dublin Airport (A) site and that available for the urban and suburban sites in June are shown in Tables 6 and 7. Rainfall was recorded on 9 days in June and with two exceptions, all stations recorded rainfall on corresponding days. The total amount of rainfall recorded at the Airport was $53.6 \mathrm{~mm}$ (Table 6), which was higher and lower than that recorded at the urban and suburban sites, respectively; this is not surprising given the non-standard exposure of the gauges at the flux sites. Recorded wind-speed at the Airport averaged $2.17 \mathrm{~ms}^{-1}$, which was lower than that measured over the 'rougher' urban surface at both sites, which may be surprising but mean wind-speed was lower than normal in June 2010 owing to the dominance of high pressure ( $1018 \mathrm{hPa}$ for the month). The difference between the sites is clearest when air temperature and solar radiation observations are compared (Table 7): $\mathrm{T}$ at the Airport is consistently lower than values in the city, especially at night and; $K \downarrow$ is higher on average especially in the morning hours. These differences are probably influenced by the local climate at the Airport, which is closer to the coast and may be affected by an afternoon sea-breeze in generally calm conditions. These types of differences might be expected of any station located 'near' the site of interest but subject to its own local influences; as such, using the observations from a WMO synoptic station (that might be expected to record the background climate) to force SUEWS is a good test of its robustness.

The hourly observed and simulated fluxes for June 2010 for both sites are presented in Fig. 2 . The diurnal cycle at the urban site shows that most of the available energy $\left(Q^{*}\right)$ is partitioned into sensible heat, either as storage in the fabric $\left(\Delta Q_{S}\right)$ or as turbulent exchange with the atmosphere $\left(Q_{H}\right)$; relatively little is expended as evaporation $\left(Q_{E}\right)$, about $10 \%\left(25 \mathrm{~W} \mathrm{~m}^{-2}\right)$ of $Q^{*}$ around noon. Before mid-day it is $\Delta Q_{S}$ that dominates but $Q_{H}$ is the largest non-radiative flux after noon. At the suburban site, the same basic pattern is present but $Q_{E}$ is larger, reaching values of $60 \mathrm{~W} \mathrm{~m}^{-2}$ in early afternoon about one-third the magnitude of $Q_{H}$. The difference in patterns between the sites reflects their respective vegetated fractions.

Overall, SUEWS reproduces the diurnal cycle and shows good agreement with the observations at both locations, even when the model is run using standard meteorological data and urban parameters derived from the LCZ dataset, rather than the site specific data (Mode 3 ). Table 8 summarises the relative differences in hourly RMSE and MFB in terms of changing the land cover and meteorological forcing data. The run with optimal model inputs (Mode 1) uses measured values of $K \downarrow$ and $L \downarrow$ are provided by the observation platforms so not surprisingly $Q^{*}$ is simulated closely at both sites (RMSE $\approx 10 \mathrm{~W} \mathrm{~m}^{-2}$ with little bias). The error for $K \uparrow$ is 3.5 and $20.2 \mathrm{~W} \mathrm{~m}^{-2}$ at the urban and suburban sites, respectively. Noticeably the bias and error in the simulation at the suburban site $(\mathrm{MFB}=0.55)$

Table 6

Daily rainfall receipt at Dublin Airport (RA) and the difference recorded at the urban $\left(\Delta R_{A-U}\right)$ and suburban $\left(\Delta R_{A-S}\right)$ flux sites.

\begin{tabular}{llll}
\hline Day & $\mathrm{RA}(\mathrm{mm})$ & $\Delta R_{A-U}$ & $\Delta R_{A-S}$ \\
\hline June 1 & 14.20 & -6.20 & -8.20 \\
June 7 & 7.80 & -1.80 & -6.20 \\
June 8 & 15.20 & 7.40 & .60 \\
June 9 & 1.00 & -.60 & -.60 \\
June 10 & .20 & .00 & .20 \\
June 14 & 11.80 & 5.60 & 1.40 \\
June 27 & 2.70 & 1.70 & 1.10 \\
June 28 & .00 & -1.60 & -.20 \\
June 29 & .70 & .70 & .50 \\
Total & 53.6 & 5.2 & -11.4 \\
\hline
\end{tabular}


Table 7

Mean hourly wind speed $\left(V_{\mathrm{A}}\right)$, air temperature $\left(T_{\mathrm{A}}\right)$, and shortwave radiation receipt $\left(K \downarrow_{A}\right)$ at Dublin Airport and the differences $(\Delta)$ recorded at the urban $(u)$ and suburban $(s)$ flux sites.

\begin{tabular}{|c|c|c|c|c|c|c|c|c|c|}
\hline Hour & $V_{A}$ & $\Delta V_{A-U}$ & $\Delta V_{A-S}$ & $T_{A}$ & $\Delta T_{A-U}$ & $\Delta T_{A-S}$ & $K \downarrow_{A}$ & $\Delta K \downarrow_{A-U}$ & $\Delta K \downarrow_{A-S}$ \\
\hline 0 & 1.70 & -0.40 & -0.50 & 11.37 & -4.43 & -5.03 & .0 & .0 & .0 \\
\hline 1 & 1.83 & -0.31 & -0.39 & 11.20 & -4.15 & -4.63 & .0 & .0 & .0 \\
\hline 2 & 1.81 & -0.29 & -0.40 & 10.70 & -4.15 & -4.70 & .0 & .0 & .0 \\
\hline 3 & 1.84 & -0.33 & -0.42 & 10.46 & -4.02 & -4.81 & .0 & .0 & .0 \\
\hline 4 & 1.74 & -0.25 & -0.54 & 10.61 & -3.75 & -4.79 & 2.1 & 1.7 & 1.7 \\
\hline 5 & 1.63 & -0.35 & -0.50 & 11.32 & -3.15 & -4.36 & 38.7 & 11.6 & 7.8 \\
\hline 6 & 1.82 & -0.18 & -0.48 & 12.36 & -2.49 & -3.94 & 108.8 & 20.7 & 12.7 \\
\hline 7 & 2.05 & -0.21 & -0.62 & 13.59 & -1.96 & -3.15 & 194.9 & 30.1 & 9.1 \\
\hline 8 & 2.25 & -0.33 & -0.62 & 14.58 & -1.86 & -2.70 & 311.6 & 43.1 & 9.8 \\
\hline 9 & 2.35 & -0.42 & -0.83 & 15.35 & -1.48 & -2.45 & 385.6 & 22.4 & -3.5 \\
\hline 10 & 2.43 & -0.54 & -0.76 & 16.20 & -1.30 & -2.10 & 487.4 & -2.6 & 20.78 \\
\hline 11 & 2.49 & -0.46 & -0.78 & 16.71 & -1.30 & -1.83 & 569.1 & 60.5 & 37.8 \\
\hline 12 & 2.57 & -0.49 & -0.82 & 17.03 & -1.44 & -1.84 & 546.9 & 32.2 & 57.9 \\
\hline 13 & 2.58 & -0.83 & -1.06 & 17.47 & -1.30 & -1.53 & 559.4 & 27.6 & 43.8 \\
\hline 14 & 2.55 & -0.83 & -1.30 & 17.63 & -1.35 & -1.59 & 524.4 & -6.7 & 12.8 \\
\hline 15 & 2.59 & -0.79 & -1.29 & 17.73 & -1.56 & -1.55 & 460.3 & -29.1 & 28.9 \\
\hline 16 & 2.69 & -0.72 & -1.17 & 17.80 & -1.56 & -1.60 & 388.2 & -30.9 & -21.3 \\
\hline 17 & 2.58 & -0.69 & -1.28 & 17.64 & -1.72 & -1.74 & 332.4 & -7.7 & -1.7 \\
\hline 18 & 2.45 & -0.66 & -1.07 & 17.20 & -2.18 & -2.12 & 229.1 & -4.0 & -17.0 \\
\hline 19 & 2.38 & -0.52 & -0.94 & 16.62 & -2.54 & -2.49 & 116.8 & -16.2 & -12.1 \\
\hline 20 & 2.13 & -0.42 & -0.75 & 15.61 & -3.22 & -3.16 & 40.1 & -4.1 & -4.8 \\
\hline 21 & 1.92 & -0.22 & -0.58 & 14.21 & -4.10 & -3.94 & 1.9 & -1.1 & -1.0 \\
\hline 22 & 1.86 & -0.37 & -0.53 & 13.07 & -4.17 & -4.46 & .0 & .0 & .0 \\
\hline 23 & 1.73 & -0.38 & -0.51 & 12.34 & -4.28 & -4.56 & .0 & .0 & .0 \\
\hline Mean & 2.17 & -0.46 & -0.76 & 14.53 & -2.64 & -3.13 & 220.7 & 6.1 & 7.6 \\
\hline St. Dev & 0.98 & 0.79 & 0.87 & 3.60 & 1.64 & 1.97 & 255.5 & 94.6 & 76.9 \\
\hline Skewness & 0.18 & -0.15 & 0.64 & -0.18 & -0.66 & -1.05 & 1.00 & 0.20 & 1.08 \\
\hline Median & 2.22 & -0.44 & -0.79 & 14.60 & -2.40 & -2.77 & 107.0 & 0 & 0 \\
\hline Quartile 25 & 1.39 & -0.93 & -1.28 & 12.00 & -3.50 & -3.80 & 0 & -9.1 & -9.5 \\
\hline Quartile 75 & 2.78 & 0.01 & -0.27 & 17.40 & -1.50 & -1.98 & 378.5 & 21.8 & 14.6 \\
\hline
\end{tabular}

indicates persistent overestimation by SUEWS; this is not unexpected given the nature of the urban surface directly below the net radiometer at the suburban site discussed earlier, which results in a lower albedo than expected. The RMSE values for $L \uparrow$ are 30 and $20 \mathrm{~W} \mathrm{~m}^{-2}$ at the urban and suburban sites but the MFB values are close to zero. The errors in the non-radiative terms are 15 (19), 15 (17), $31(27) \mathrm{W} \mathrm{m}^{-2}$ for $Q_{H}, Q_{E}$ and $\Delta Q_{S}$, respectively for the urban and suburban sites (the latter in parentheses). The $Q_{E}$ term is overestimated at both sites (more so at the urban site where little evaporation was measured) but the overestimate in $\Delta Q_{S}$ at the suburban site is a distinguishable feature.

Running SUEWS in Mode 2 changes the source of meteorological input data, which are no longer collected in situ with the non-radiative flux terms. In addition, $L \downarrow$ is now estimated from temperature and relative humidity (Loridan et al., 2011). The effect of these changes on the radiative terms is to introduce an error into $K \downarrow$ of about $23(25) \mathrm{W} \mathrm{m}^{-2}$ and into $L \downarrow$ of about $7(7) \mathrm{W} \mathrm{m}^{-2}$, but no mean bias. The effect can be seen in the diurnal curve of $Q^{*}$ (Fig. 2b), which is lower in the daytime by about $20 \mathrm{~W} \mathrm{~m}^{-2}$ near noon and higher at night-time (less negative). However, change in RMSE is largest for $Q^{*}$ at $15(10) \mathrm{W} \mathrm{m}^{-2}$ but as $Q^{*}$ is the largest component in the energy budget, this increase is not substantial. The patterns of the non-radiative terms are broadly consistent with the observations. The changes in the hourly RMSE values for the non-radiative fluxes at both sites are not large $\left( \pm 5 \mathrm{~W} \mathrm{~m}^{-2}\right.$ ); $\Delta Q_{S}$ and $Q_{E}$ are smaller but $Q_{H}$ is larger. However these changes do affect the bias; the MFB generally increases in magnitude and, in the case of $Q_{E}$ at the urban site, the sign reverses. However, the magnitude of $Q_{E}$ at this site is very small so it is especially sensitive. Running SUEWS in Mode 3 by using the typical LCZ values (Table 5) has a minor additional impact; RMSE values changed from between 2 and $6 \mathrm{~W} \mathrm{~m}^{-2}$ at both sites. The additional error introduced to the non-radiative terms is relatively small, increasing RMSE values by about $6 \mathrm{~W} \mathrm{~m}^{-2}$. 

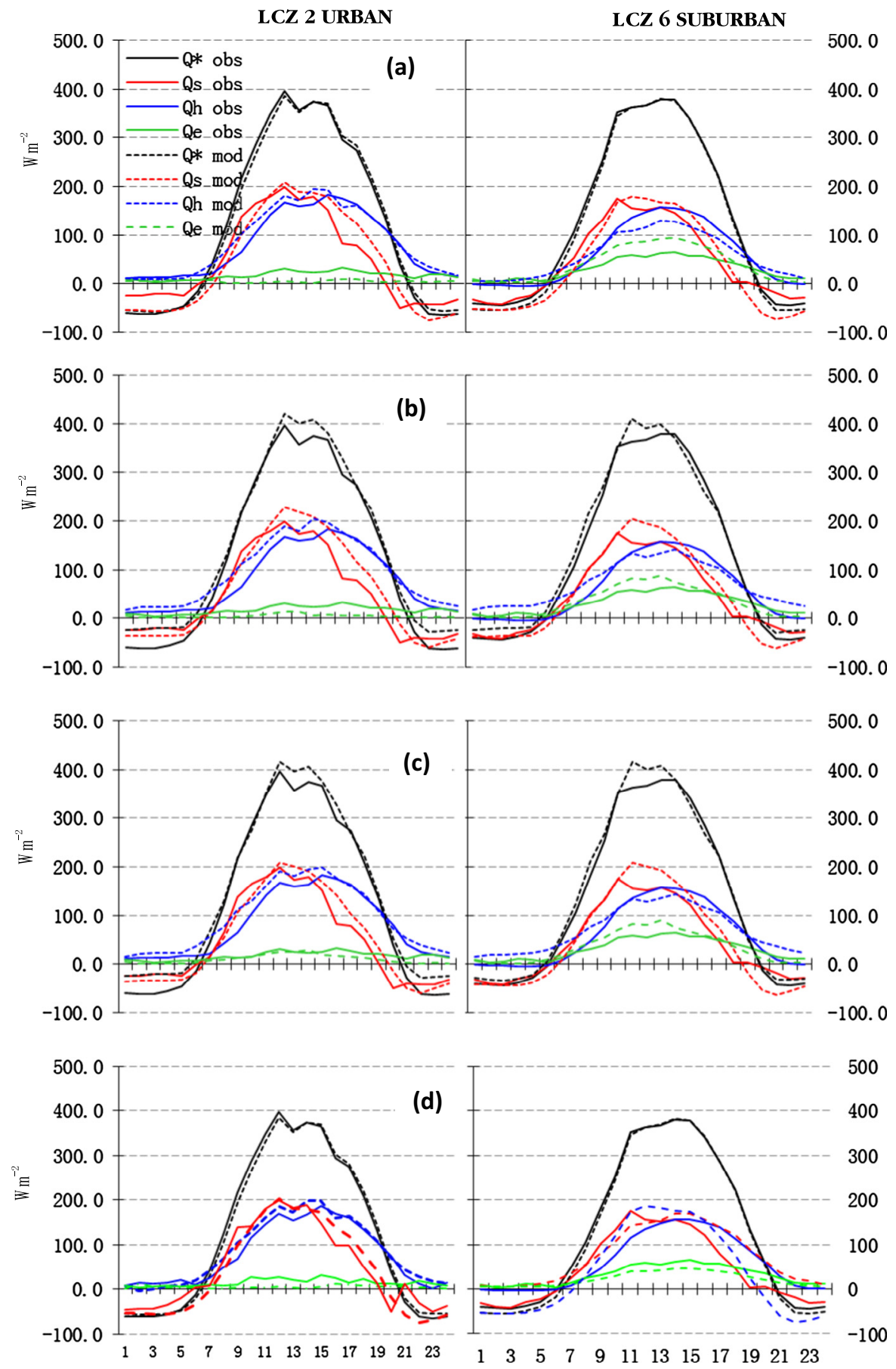

Fig. 2. Average hourly energy fluxes (measured and simulated) in $\mathrm{W} \mathrm{m}^{-2}$ for June 2010 . The graphs on the left refer to the urban site and those on the right refer to the suburban site. The rows (a-d) show simulations when SUEWS is run in different modes (a: Flux Forcing (FF) with Site Specific (SS) land cover (Mode 1), b: Synoptic Forcing (SF) with SS land cover (Mode ...), c: SF with LCZ land cover d: FF with LCZ land cover). See text for details. $X$-axis is local time. 


\section{Table 8}

Root mean square error (RMSE) and Mean Fractional Bias (MFB) and bias direction change for each energy budget term based on hourly fluxes for June 2010. The top is urban (LCZ2 site) bottom is suburban (LCZ6 site). RMSE values are in W $\mathrm{m}^{-2}$. Negative values denote a reduction in RMSE (i.e. model improvement) whereas positive values denote an increase in RMSE. Negative values in MFB denote a decrease in absolute bias, positive denotes an increase in absolute bias. MFB directional changes denote if the model switches $(>)$ from over $(+)$ to under $(-)$ prediction or if the direction of the bias remains the same $(=)$.

\begin{tabular}{|c|c|c|c|c|c|c|}
\hline & \multicolumn{3}{|c|}{ Degrading meteorological forcing } & \multicolumn{3}{|c|}{ Degrading land cover } \\
\hline & RMSE & MFB & MFB direction & RMSE & MFB & MFB direction \\
\hline \multicolumn{7}{|l|}{$L C Z 2$} \\
\hline$Q^{*}$ & 16.5 & 0.17 & $=$ & -0.9 & -0.01 & $=$ \\
\hline$K \downarrow$ & - & - & & 0 & 0 & $=$ \\
\hline$K \uparrow$ & 3 & 0.03 & $=$ & 2.2 & 0.06 & $=$ \\
\hline$L \downarrow$ & - & - & & 0 & 0 & $=$ \\
\hline$L \uparrow$ & -11.7 & -0.03 & $=$ & -0.1 & 0 & $=$ \\
\hline$\Delta Q_{S}$ & -3.5 & 0.26 & $->+$ & -6 & -0.13 & $=$ \\
\hline$Q_{H}$ & 6.1 & 0.09 & $=$ & -1.2 & -0.01 & $=$ \\
\hline$Q_{E}$ & -0.3 & -0.15 & $=$ & -5.6 & 0.72 & $=$ \\
\hline \multicolumn{7}{|l|}{ LCZ6 } \\
\hline$Q^{*}$ & 9.7 & 0.14 & $->+$ & -1.7 & -0.01 & $=$ \\
\hline$K \downarrow$ & - & - & & 0 & 0 & $=$ \\
\hline$K \uparrow$ & 4.7 & 0.02 & $=$ & -1.5 & -0.02 & $=$ \\
\hline$L \downarrow$ & - & - & & 0 & 0 & $=$ \\
\hline$L \uparrow$ & 3.5 & -0.03 & $=$ & -0.2 & 0 & $=$ \\
\hline$\Delta Q_{S}$ & -4.1 & 0.28 & $->+$ & 2.5 & -0.02 & $=$ \\
\hline$Q_{H}$ & 4.4 & 0.2 & $->+$ & -2.3 & -0.01 & $=$ \\
\hline$Q_{E}$ & -4.5 & -0.14 & $=$ & 0.1 & 0 & $=$ \\
\hline
\end{tabular}

Running the model in Mode 3 has little effect. Similarly the difference between Modes 1 and 4 where the difference is in land cover representation utilising meteorology from the flux sites were negligible; at both sites the radiative RMSE difference was $<1.0 \mathrm{~W} \mathrm{~m}^{-2}$ and difference in RMSE for the turbulent fluxes was $<2.0 \mathrm{~W} \mathrm{~m}^{-2}$.

Overall, the difference in the urban environments around each site is captured by the model; this is clearest in the $Q_{E}$ differences between sites that correspond with their respective vegetated fractions. Most of the errors associated with using sub-optimum input data is associated with the use of off-site meteorological inputs that affected the incoming radiative terms ( $K \downarrow$ and $L \downarrow)$ most directly. However, the suburban site consistent overestimation of $K \uparrow$ suggests strongly that there is a discrepancy between the site-specific albedo and that of the neighbourhood generally. The diurnal and daily patterns of exchanges are simulated by SUEWS but there are obvious issues with simulating $Q_{E}$ at both sites. The difference in running the model in Mode 2 and Mode 3 is small, which suggests that the use of off-site meteorological input data is of greater significance than the use of the LCZ-based evaluation of urban land-cover.

\subsection{Daily fluxes comparison}

Table 9 shows the average daily RMSE scores for each of the flux terms by month and by Mode for the urban and suburban observation sites. Thus, for example, for the entire period at the urban site, the average RMSE values for SUEWS run in Mode 1 are: $21.7\left(\mathrm{RMSE}_{\mathrm{Q}_{*}}\right) ; 25.3\left(\mathrm{RMSE}_{\Delta \mathrm{QS}}\right) ; 23.9\left(\mathrm{RMSE}_{\mathrm{QH}}\right)$ and; $16.7 \mathrm{~W} \mathrm{~m}^{-2}$ (RMSE $\left.\mathrm{RE}_{\mathrm{QE}}\right)$. The total $\left(\Sigma_{\mathrm{RMSE}}\right)$ error $\left(87.6 \mathrm{~W} \mathrm{~m}^{-2}\right)$ is the sum of the individual flux error terms and is a useful measure of overall model performance. For the optimal case (Mode 1 ) the $\Sigma_{\mathrm{RMSE}}$ for the urban site is $89.1 \mathrm{~W} \mathrm{~m}^{-2}$ while that for the suburban site is $83.3 \mathrm{~W} \mathrm{~m}^{-2}$. The overall performance is also presented in Fig. 3.

Changing the land-cover and meteorological data input data had little impact on the overall performance of the model. For the urban site, $\Sigma_{\text {RMSE }}$ values are $90.3,82.7$ and $92.6 \mathrm{~W} \mathrm{~m}^{-2}$ for Modes 2,3 and 4 , respectively. Similarly, for the suburban site, the differences compared to Mode 1 are all $<5.5 \mathrm{~W} \mathrm{~m}^{-2}$. The best performance (i.e. the lowest $\Sigma_{\mathrm{RMSE}}$ ) was found in Mode 1 for the LCZ6 site 
Table 9

Root mean square error (RMSE) values $\left(\mathrm{W} \mathrm{m}^{-2}\right.$ ) for each month based on daily values of all flux terms for each Mode ( $N=744$ per Mode) Mode 1 uses High-Resolution land cover (HRLC) and forcing data obtained at the flux sites, Mode 2 uses HRLC and forcing data obtained off-site by a standard weather station. Mode 3 uses LCZ derived land cover fractions and off-site forcing data. Finally Mode 4 uses LCZ land cover and forcing data obtained at the flux sites.

\begin{tabular}{|c|c|c|c|c|c|c|c|c|c|c|c|c|c|c|c|c|c|}
\hline Flux & April & May & June & July & August & September & October & Mean & Flux & April & May & June & July & August & September & October & Mean \\
\hline \multicolumn{18}{|c|}{ Urban site (LCZ1) } \\
\hline$Q^{*}$ & 24.1 & 26.0 & 27.6 & 19.7 & 21.8 & 18.7 & 14.0 & 22.1 & $\overline{Q^{*}}$ & 22.8 & 26.9 & 29.4 & 17.0 & 27.8 & 18.3 & 20.3 & 23.4 \\
\hline$\Delta Q_{S}$ & 18.7 & 34.1 & 28.2 & 35.1 & 25.6 & 16.4 & 19.1 & 26.0 & $\Delta Q_{S}$ & 15.6 & 32.5 & 27.0 & 30.7 & 24.6 & 17.2 & 27.0 & 25.2 \\
\hline$Q_{H}$ & 21.2 & 24.9 & 19.2 & 24.2 & 20.4 & 26.7 & 30.8 & 23.6 & $Q_{H}$ & 21.1 & 24.4 & 21.0 & 24.2 & 23.1 & 25.2 & 26.3 & 23.5 \\
\hline$Q_{E}$ & 11.1 & 18.8 & 18.0 & 20.9 & 16.2 & 22.5 & 9.5 & 17.4 & $Q_{E}$ & 11.3 & 19.7 & 18.8 & 21.0 & 16.5 & 24.6 & 9.7 & 18.1 \\
\hline \multirow[t]{2}{*}{ SUM } & & & & & & & & 89.1 & SUM & & & & & & & & 90.2 \\
\hline & \multicolumn{9}{|c|}{ Mode 3} & \multicolumn{8}{|c|}{ Mode 4} \\
\hline$Q^{*}$ & 21.8 & 25.9 & 28.0 & 16.5 & 26.9 & 17.7 & 20.1 & 22.6 & $Q^{*}$ & 36.7 & 33.4 & 31.0 & 28.8 & 26.2 & 25.0 & 21.1 & 29.1 \\
\hline$\Delta Q_{S}$ & 13.3 & 29.2 & 21.6 & 26.8 & 20.7 & 16.7 & 27.8 & 22.3 & $\Delta Q_{S}$ & 20.0 & 32.5 & 24.7 & 34.2 & 22.8 & 17.2 & 28.5 & 25.8 \\
\hline$Q_{H}$ & 21.3 & 24.5 & 20.6 & 23.1 & 22.5 & 23.8 & 25.7 & 23.0 & $Q_{H}$ & 26.8 & 27.7 & 19.2 & 24.9 & 21.3 & 26.1 & 26.6 & 24.5 \\
\hline$Q_{E}$ & 8.5 & 16.6 & 14.6 & 16.3 & 12.7 & 22.3 & 8.6 & 14.8 & $Q_{E}$ & 7.8 & 15.9 & 13.5 & 16.6 & 12.2 & 19.7 & 8.0 & 13.9 \\
\hline SUM & & & & & & & & 82.7 & SUM & & & & & & & & 92.6 \\
\hline \multicolumn{18}{|c|}{ Suburban site (LCZ6) } \\
\hline & \multicolumn{9}{|c|}{ Mode 1} & \multicolumn{8}{|c|}{ Mode 2} \\
\hline$Q^{*}$ & 18.5 & 21.5 & 17.8 & 14.7 & 14.3 & 13.4 & 5.9 & 15.6 & $\overline{Q^{*}}$ & 15.5 & 21.9 & 26.7 & 23.8 & 19.1 & 15.2 & 13.6 & 19.9 \\
\hline$\Delta Q_{S}$ & 18.4 & 19.8 & 18.2 & 17.0 & 19.1 & 24.2 & 36.7 & 21.1 & $\Delta Q_{S}$ & 23.8 & 23.3 & 22.2 & 20.3 & 17.7 & 25.3 & 35.1 & 23.2 \\
\hline$Q_{H}$ & 15.1 & 25.2 & 16.5 & 23.0 & 16.6 & 30.3 & 30.9 & 22.2 & $Q_{H}$ & 11.9 & 21.1 & 17.3 & 19.9 & 16.0 & 28.2 & 30.5 & 20.4 \\
\hline$Q_{E}$ & 13.9 & 15.0 & 17.8 & 30.8 & 21.4 & 42.7 & 28.1 & 24.3 & $Q_{E}$ & 11.3 & 14.1 & 17.1 & 28.2 & 22.9 & 45.3 & 28.7 & 24.1 \\
\hline \multirow[t]{2}{*}{ SUM } & & & & & & & & 83.3 & SUM & & & & & & & & 87.6 \\
\hline & \multicolumn{9}{|c|}{ Mode 3} & \multicolumn{8}{|c|}{ Mode 4} \\
\hline$Q^{*}$ & 15.4 & 22.2 & 27.1 & 23.7 & 19.3 & 15.4 & 13.6 & 20.1 & $\overline{Q^{*}}$ & 15.8 & 19.0 & 23.1 & 14.1 & 14.0 & 14.4 & 17.1 & 16.8 \\
\hline$\Delta Q_{S}$ & 22.6 & 22.7 & 22.1 & 20.4 & 17.8 & 25.2 & 34.8 & 23.0 & $\Delta Q_{S}$ & 21.9 & 22.1 & 20.5 & 17.1 & 22.1 & 25.4 & 29.6 & 22.2 \\
\hline$Q_{H}$ & 14.8 & 23.4 & 19.4 & 19.9 & 18.1 & 30.3 & 33.2 & 22.3 & $Q_{H}$ & 14.6 & 24.9 & 18.6 & 23.4 & 17.6 & 31.8 & 38.2 & 23.6 \\
\hline$Q_{E}$ & 7.7 & 13.5 & 14.0 & 29.5 & 23.4 & 46.4 & 28.1 & 23.5 & $Q_{E}$ & 8.7 & 13.5 & 13.6 & 31.9 & 21.8 & 44.0 & 27.9 & 23.3 \\
\hline SUM & & & & & & & & 88.8 & SUM & & & & & & & & 85.9 \\
\hline
\end{tabular}




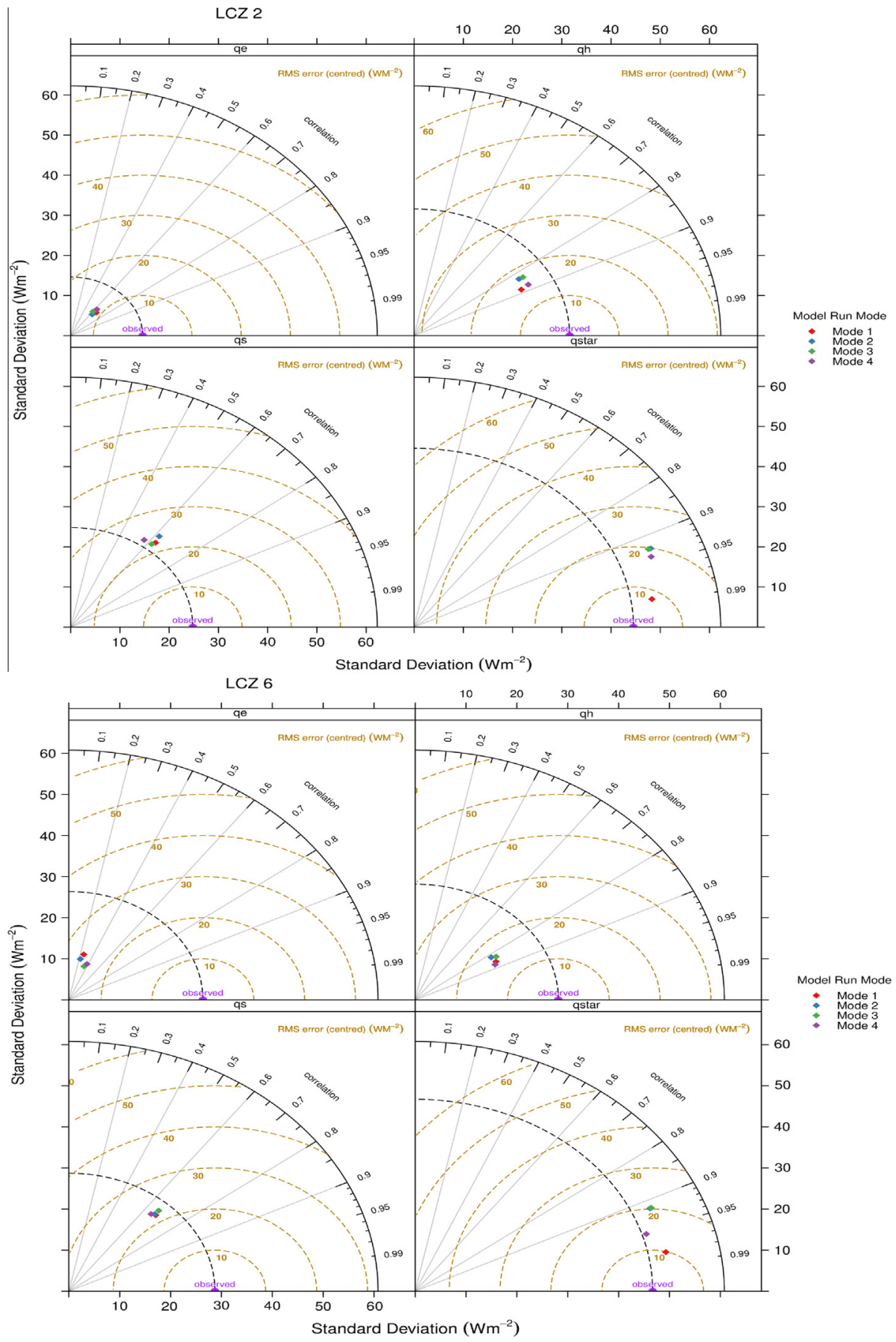

Fig. 3. Taylor diagrams for Mode 1-4 based on daily values of $Q_{E}, Q_{H}, \Delta Q_{S}$ and $Q *$ for LCZ2 (top) and LCZ6 (bottom) Mode 1 uses High-Resolution land cover (HRLC) and forcing data obtained at the flux sites, Mode 2 uses HRLC and forcing data obtained offsite by a standard weather station. Mode 3 uses LCZ derived land cover fractions and off-site forcing data. Finally Mode 4 uses LCZ land cover and forcing data obtained at the flux sites. 
and Mode 3 for the LCZ2 site. The worst performance (highest $\Sigma_{\text {RMSE }}$ ) was found in Mode 3 and Mode 4 for the LCZ6 and LCZ2 site respectively. The difference between the best and worst performances was $5.5 \mathrm{~W} \mathrm{~m}^{-2}$ for the LCZ6 site and approximately double this $\left(9.9 \mathrm{~W} \mathrm{~m}^{-2}\right)$ for the LCZ2 site. The range of RMSE across all fluxes was $<30 \mathrm{~W} \mathrm{~m}^{-2}$ for the LCZ2 site in all Modes and was $<40 \mathrm{~W} \mathrm{~m}^{-2}$ for the LCZ6 site in all modes.

Examining the individual flux performance more closely looking firstly at $Q^{*}$; the lowest mean RMSE value was $22.1 \mathrm{~W} \mathrm{~m}^{-2}$ for the LCZ2 site in Mode 1 and $15.6 \mathrm{~W} \mathrm{~m}^{-2}$ for the LCZ6 site, also in Mode 1. The highest mean RMSE value for $Q^{*}$ was $29.1 \mathrm{~W} \mathrm{~m}^{-2}$ in Mode 4 for the LCZ2 site and $20.1 \mathrm{~W} \mathrm{~m}^{-2}$ for the LCZ6 site in Mode 3. Given the relatively large magnitude of this flux, this may be regarded as negligible. For the turbulent fluxes $\left(Q_{H}\right.$ and $\left.Q_{E}\right)$, the lowest mean RMSE value for $Q_{H}$ and $Q_{E}$ (respectively) was $23.0 \mathrm{~W} \mathrm{~m}^{-2}$ (Mode 3) and $13.9 \mathrm{~W} \mathrm{~m}^{-2}$ (Mode 4) for the LCZ2 site and $20.4 \mathrm{~W} \mathrm{~m}^{-2}$ (Mode 2) and $23.6 \mathrm{~W} \mathrm{~m}^{-2}$ (Mode 4) for the LCZ6 site. $\Delta Q_{S}$ mean RMSE ranged between a minimum of $22.3 \mathrm{~W} \mathrm{~m}^{-2}$ (in Mode 2) and maximum of $26.0 \mathrm{~W} \mathrm{~m}^{-2}$ (in Mode 1) for the LCZ2 site and a minimum of $21.1 \mathrm{~W} \mathrm{~m}^{-2}$ (in Mode 1) and maximum of $23.2 \mathrm{~W} \mathrm{~m}^{-2}$ (in Mode 3) for the LCZ6 site.

In general, the model was consistently biased (MFB) across all months and all Modes. The model exhibited a minor positive bias $(<0.5)$ for both $Q^{*}$ and $Q_{H}$ for both sites in all Modes. For both sites, $\Delta Q_{S}$ exhibited a strong negative bias $(<-1.0)$ in all Modes, whereas $Q_{E}$ varied between a strong negative bias for the LCZ2 site and a minor negative bias for the LCZ6 site (see Table 10).

\subsection{Impact of meteorological forcing data on performance}

Comparing model performance between Mode 1 to Mode 2 and Mode 4 to Mode 3 reveals an insight into the impact of meteorological forcing data when utilising the same quality of land cover information. This is summarised by Table 11. For the high-resolution land cover cases, utilising off-site meteorological data to force SUEWS decreased the performance (i.e. increase RMSE) of $Q^{*}$ by $1.5 \mathrm{~W} \mathrm{~m}^{-2}$ for the LCZ2 site and by $4.2 \mathrm{~W} \mathrm{~m}^{-2}$ for the LCZ6 site. This decrease in performance did not cascade through all turbulent fluxes, model performance increased (i.e. decreased RMSE) marginally for $Q_{H}$ and $\Delta Q_{S}$ (by 0.4 and $0.3 \mathrm{~W} \mathrm{~m}^{-2}$ respectively) for the LCZ2 site whereas RMSE was increased by $0.7 \mathrm{~W} \mathrm{~m}^{-2}$ for $Q_{E}$. For the LCZ6 site, RMSE for $Q_{H}$ decreased by $1.8 \mathrm{~W} \mathrm{~m}^{-2}$ and by $0.3 \mathrm{~W} \mathrm{~m}^{-2}$ for $Q_{E}$ when utilising off-site meteorology, $\Delta Q_{S}$ RMSE increased by $2.0 \mathrm{~W} \mathrm{~m}^{-2}$. Accounting for performance increases and decreases, the mean RMSE difference taken across all the turbulent fluxes for both sites is $0 \mathrm{~W} \mathrm{~m}^{-2}$. By including off-site meteorological data for the Modes which utilised LCZ land cover information, RMSE decreased by $6.5,3.4$ and $1.6 \mathrm{~W} \mathrm{~m}^{-2}$ for $Q^{*}, \Delta Q_{S}$ and $Q_{H}$ respectively for the LCZ2 site. RMSE for $Q_{E}$ increased by $0.8 \mathrm{~W} \mathrm{~m}^{-2}$ For the LCZ6 site, RMSE increased by $2.7,1.0$ and $0.2 \mathrm{~W} \mathrm{~m}^{-2}$ for $Q^{*}, \Delta Q_{S}$ and $Q_{E}$ respectively. RMSE for $Q_{H}$ decreased by $1.4 \mathrm{~W} \mathrm{~m}^{-2}$. MFB direction did not change between Modes.

The impact of meteorological forcing data had a larger impact on $\Delta Q_{S}$ and $Q_{H}$ than for $Q_{E}$. This was also borne out during our OFAT analysis over a grid with equal distribution of urban, paved, and vegetated and tree cover. Differences in $K \downarrow$ had the largest impact on simulated turbulent fluxes, followed by temperature. The model was insensitive to variation in wind speed $(V)$ - see Fig. 4 . The mean difference in daily RMSE across both sites for all fluxes and all months when using off-site meteorological data in place of on-site was $\sim 0.7 \mathrm{~W} \mathrm{~m}^{-2}$.

\subsection{Impact of land cover on performance}

Table 11 also presents the impact on relative performance when land cover data are changed. Using on site meteorological forcing data (Mode 1) and subsequently utilising LCZ for land cover (Mode 4) had a larger impact on the performance of $Q^{*}$ for both sites. For the LCZ2 site, RMSE increased by $7.2 \mathrm{~W} \mathrm{~m}^{-2}$ (to $28.9 \mathrm{~W} \mathrm{~m}^{-2}$ ) for $Q^{*}$ when employing the LCZ data. Again, given the large magnitude of this flux this is rather small. As for the turbulent fluxes, $Q_{H}$ RMSE increased by $<1 \mathrm{~W} \mathrm{~m}^{-2}$ $\left(0.7 \mathrm{~W} \mathrm{~m}^{-2}\right), Q_{E}$ decreased (i.e. improved model performance) by $3.3 \mathrm{~W} \mathrm{~m}^{-2}$ and $\Delta Q_{S}$ increased by $0.4 \mathrm{~W} \mathrm{~m}^{-2}$. For the LCZ6 site, again comparing Modes which utilised on-site meteorological forcing, RMSE for $Q^{*}$ increased by $1.6 \mathrm{~W} \mathrm{~m}{ }^{-2}$ when utilising the $\mathrm{LCZ}$, by $1.5 \mathrm{~W} \mathrm{~m}^{-2}$ for $Q_{H}, 0.8 \mathrm{~W} \mathrm{~m}^{-2}$ for $\Delta Q_{S}$ and decreased by $1.2 \mathrm{~W} \mathrm{~m}^{-2}$ for $Q_{E}$. There was no impact on model bias between Modes 1 and 
Table 10

Mean Fractional Bias (MFB) results for urban (LCZ2) site and suburban (LCZ6) site April-October. Mode 1 uses High-Resolution land cover (HRLC) and forcing data obtained at the flux sites. Mode 2 uses HRLC and forcing data obtained off-site by a standard weather station. Mode 3 uses LCZ derived land cover fractions and off-site forcing data. Finally Mode 4 uses LCZ land cover and forcing data obtained at the flux sites.

\begin{tabular}{|c|c|c|c|c|c|c|c|c|c|c|c|c|c|c|c|c|}
\hline & \multicolumn{8}{|l|}{ LCZ2 } & \multicolumn{8}{|l|}{ LCZ6 } \\
\hline & April & May & June & July & August & September & October & Mean & April & May & June & July & August & September & October & $\overline{\text { Mean }}$ \\
\hline \multicolumn{17}{|l|}{$Q^{*}$} \\
\hline Mode1 & 0.22 & 0.20 & 0.20 & 0.16 & 0.20 & 0.26 & 0.27 & 0.21 & 0.12 & 0.16 & 0.11 & 0.11 & 0.10 & 0.15 & 0.02 & 0.11 \\
\hline Mode2 & 0.18 & 0.13 & 0.17 & 0.05 & 0.16 & 0.15 & 0.02 & 0.12 & -0.03 & 0.04 & 0.08 & -0.07 & 0.05 & 0.00 & -0.02 & 0.01 \\
\hline Mode3 & 0.16 & 0.12 & 0.16 & 0.04 & 0.15 & 0.14 & 0.00 & 0.11 & -0.02 & 0.04 & 0.08 & -0.06 & 0.05 & 0.01 & -0.02 & 0.01 \\
\hline Mode4 & 0.31 & 0.24 & 0.19 & 0.21 & 0.20 & 0.28 & 0.05 & 0.21 & 0.02 & 0.11 & 0.11 & 0.05 & 0.09 & 0.12 & 0.25 & 0.11 \\
\hline \multicolumn{17}{|l|}{$\Delta Q_{s}$} \\
\hline Mode1 & 0.37 & 0.49 & 0.47 & 0.72 & 0.59 & 0.24 & -1.12 & 0.25 & -0.27 & -0.06 & -0.09 & 0.22 & 0.11 & 0.18 & -3.60 & -0.50 \\
\hline Mode2 & 0.30 & 0.39 & 0.43 & 0.57 & 0.55 & -0.04 & -1.63 & 0.08 & -0.55 & -0.26 & -0.14 & -0.08 & 0.02 & -0.35 & -3.95 & -0.76 \\
\hline Mode3 & 0.14 & 0.26 & 0.31 & 0.43 & 0.41 & -0.30 & -1.41 & -0.02 & -0.49 & -0.20 & -0.08 & -0.02 & 0.08 & -0.23 & -3.82 & -0.68 \\
\hline Mode4 & 0.39 & 0.44 & 0.35 & 0.68 & 0.49 & 0.10 & -1.97 & 0.07 & -0.40 & -0.08 & -0.04 & 0.18 & 0.14 & 0.19 & -2.16 & -0.31 \\
\hline \multicolumn{17}{|l|}{$Q_{F}$} \\
\hline Mode1 & -1.17 & -1.29 & -1.32 & -1.19 & -0.97 & -0.88 & -1.06 & -1.13 & 0.44 & 0.04 & 0.19 & -0.26 & -0.09 & -0.54 & -0.18 & -0.06 \\
\hline Mode2 & -1.21 & -1.39 & -1.42 & -1.21 & -1.03 & -1.02 & -1.22 & -1.22 & 0.35 & 0.04 & 0.15 & -0.27 & -0.13 & -0.62 & -0.33 & -0.12 \\
\hline Mode3 & -0.56 & -0.85 & -0.68 & -0.75 & -0.55 & -0.69 & -0.89 & -0.71 & 0.15 & -0.15 & -0.01 & -0.43 & -0.29 & -0.74 & -0.48 & -0.28 \\
\hline Mode4 & -0.41 & -0.76 & -0.56 & -0.74 & -0.47 & -0.55 & -0.68 & -0.59 & 0.23 & -0.14 & 0.03 & -0.47 & -0.28 & -0.67 & -0.52 & -0.26 \\
\hline \multicolumn{17}{|l|}{$Q_{H}$} \\
\hline Mode1 & 0.27 & 0.21 & 0.19 & 0.15 & 0.21 & 0.47 & 0.74 & 0.32 & 0.22 & 0.32 & 0.15 & 0.23 & 0.20 & 0.84 & 1.17 & 0.45 \\
\hline Mode2 & 0.25 & 0.17 & 0.18 & 0.08 & 0.20 & 0.44 & 0.66 & 0.28 & 0.14 & 0.21 & 0.15 & 0.07 & 0.16 & 0.79 & 1.18 & 0.38 \\
\hline Mode3 & 0.25 & 0.18 & 0.17 & 0.06 & 0.18 & 0.41 & 0.65 & 0.27 & 0.20 & 0.26 & 0.20 & 0.13 & 0.23 & 0.84 & 1.23 & 0.44 \\
\hline Mode4 & 0.33 & 0.25 & 0.18 & 0.19 & 0.20 & 0.46 & 0.65 & 0.32 & 0.20 & 0.32 & 0.21 & 0.25 & 0.26 & 0.88 & 1.29 & 0.49 \\
\hline
\end{tabular}




\section{Table 11}

The impact of degrading meteorological forcing data (top Mode 1 versus Mode 2) and land cover (bottom, Mode 1 versus Mode 4 ) on daily RMSE values for the LCZ2 and LCZ6 site. Values are in $\mathrm{W} \mathrm{m}^{-2}$, negative values denote a reduction in RMSE (i.e. model improvement) whereas positive values denote an increase in RMSE.

\begin{tabular}{|c|c|c|c|c|c|c|c|}
\hline & April & May & June & July & August & September & October \\
\hline \multicolumn{8}{|c|}{ Impact of degrading forcing data on daily RMSE values } \\
\hline$Q^{*}$ & -1.3 & 0.9 & 1.8 & -2.7 & 6.0 & -0.4 & 6.3 \\
\hline$\Delta Q_{S}$ & -3.1 & -1.6 & -1.2 & -4.4 & -1.0 & 0.8 & 7.9 \\
\hline$Q_{H}$ & -0.1 & -0.5 & 1.8 & 0.0 & 2.7 & -1.5 & -4.5 \\
\hline$Q_{E}$ & 0.2 & 0.9 & 0.8 & 0.1 & 0.3 & 2.1 & 0.2 \\
\hline \multicolumn{8}{|c|}{ LCZ6 } \\
\hline$Q^{*}$ & -3.0 & 0.4 & 8.9 & 9.1 & 4.8 & 1.8 & 7.7 \\
\hline$\Delta Q_{S}$ & 5.4 & 3.5 & 4.0 & 3.3 & -1.4 & 1.1 & -1.6 \\
\hline$Q_{H}$ & -3.2 & -4.1 & 0.8 & -3.1 & -0.6 & -2.1 & -0.4 \\
\hline$Q_{E}$ & -2.6 & -0.9 & -0.7 & -2.6 & 1.5 & 2.6 & 0.6 \\
\hline \multicolumn{8}{|c|}{$\begin{array}{l}\text { Impact of degrading land cover quality on daily RMSE values } \\
\text { LCZ2 }\end{array}$} \\
\hline$Q^{*}$ & -1.0 & -1.0 & -1.4 & -0.5 & -0.9 & -0.6 & -0.2 \\
\hline$\Delta Q_{S}$ & -2.3 & -3.3 & -5.4 & -3.9 & -3.9 & -0.5 & 0.8 \\
\hline $\mathrm{Q}_{H}$ & 0.2 & 0.1 & -0.4 & -1.1 & -0.6 & -1.4 & -0.6 \\
\hline$Q_{E}$ & -2.8 & -3.1 & -4.2 & -4.7 & -3.8 & -2.3 & -1.1 \\
\hline \multicolumn{8}{|c|}{ LCZ6 } \\
\hline$Q^{*}$ & 0.1 & -0.3 & -0.4 & 0.1 & -0.2 & -0.2 & 0.0 \\
\hline$\Delta Q_{S}$ & 1.2 & 0.6 & 0.1 & -0.1 & -0.1 & 0.1 & 0.3 \\
\hline$Q_{H}$ & -2.9 & -2.3 & -2.1 & 0.0 & -2.1 & -2.1 & -2.7 \\
\hline$Q_{E}$ & 3.6 & 0.6 & 3.1 & -1.3 & -0.5 & -1.1 & 0.6 \\
\hline
\end{tabular}

Sensitivity of mean flux values of $Q H, Q E \& \Delta Q S$ to meteorological forcing ( $\mathrm{K} \downarrow$, Tair \& U) $\pm 10 \%$ relative to base case

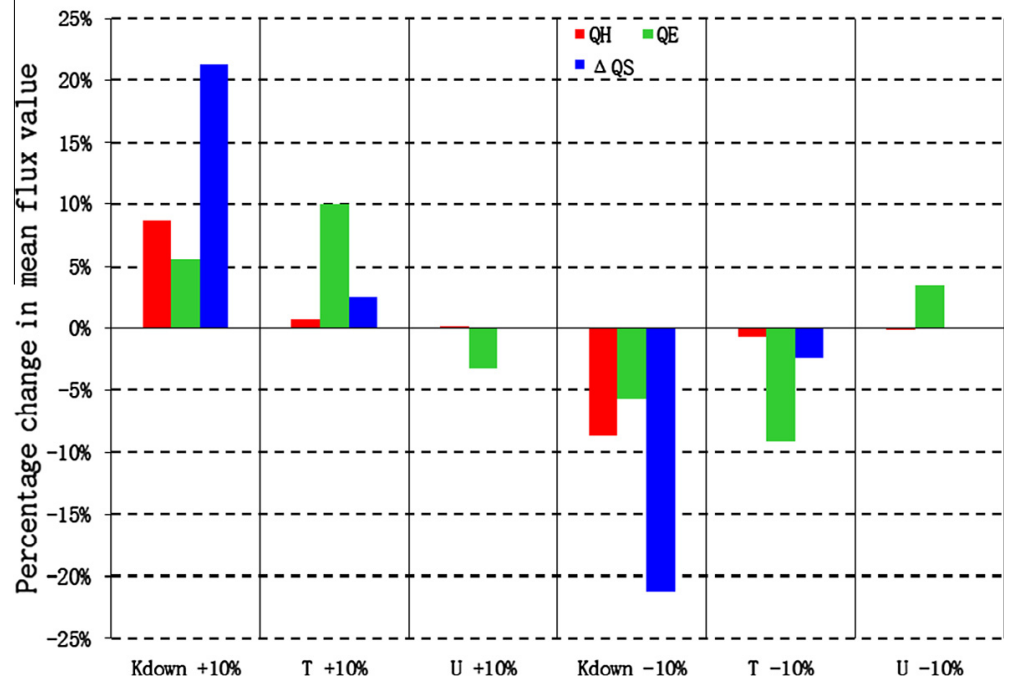

Fig. 4. One-Factor-A-Time (OFAT) sensitivity analysis of forcing data impact on SUEWS simulation of turbulent fluxes. A base case $(168 \mathrm{~h}$ ) was established using data derived from loess curve (least square) of required meteorological forcing (see Table 3 ). We then perturbed $K \downarrow, T$ and $u \pm 10 \%$ of the base case. Presented above is the \% difference in the mean value (over the $168 \mathrm{~h}$ ) of $Q_{H}, Q_{E}$ and $\Delta Q_{S}$. It should be noted that $R H$ was not modified when perturbing $T$, hence the apparent increase/decrease in $Q_{E}$. 
4 and Modes 2 and 3 with the exception of $\Delta Q_{S}$ for the LCZ2 site, where the model exhibited a minor positive MFB (over-prediction) of heat storage in Mode $1(0.25)$, and a close to zero $(-0.07)$ negative MFB in Mode 4.

Examining the impact of land cover input when off-site meteorological forcing data was utilised (i.e. comparing Mode 2 and Mode 3), often a net improvement in model performance was observed when utilising the LCZ data. However as with the performance changes arising between the on-site meteorological Modes, the changes here can be summarised as marginal improvements. Utilising the LCZ for the LCZ2 site improved model performance by $0.8 \mathrm{~W} \mathrm{~m}^{-2}$ for $Q^{*}, 2.6 \mathrm{~W} \mathrm{~m}^{-2}$ for $\Delta Q_{S}$, $0.5 \mathrm{~W} \mathrm{~m}^{-2}$ for $Q_{H}$ and $3.3 \mathrm{~W} \mathrm{~m}^{-2}$ for $Q_{E}$. For the LCZ6 site, RMSE increased by $0.1 \mathrm{~W} \mathrm{~m}^{-2}$ for $Q^{*}$ and by $2.0 \mathrm{~W} \mathrm{~m}^{-2}$ for $Q_{H}$. RMSE decreased by $0.3 \mathrm{~W} \mathrm{~m}^{-2}$ for $\Delta Q_{S}$ and $0.7 \mathrm{~W} \mathrm{~m}^{-2}$ for $Q_{E}$. As with the on-site Modes, MFB did not change direction when utilising the LCZ for land cover. The mean difference in daily RMSE across both sites for all fluxes and all months when using LCZ land cover in place of high-resolution land cover was $\sim-1 \mathrm{~W} \mathrm{~m}^{-2}$.

\section{Discussion}

\subsection{SUEWS accuracy and measurement errors}

It would be incorrect to attribute the difference between 'best case' (Mode 1) simulations by SUEWS and site observations (i.e. performance) to model errors only. The fractional coverage values used by the model represent the surrounding neighbourhood but the observation site may still be exposed to atypical surface characteristics. This appears to be the case for the suburban site here where $K \uparrow$ is consistently overestimated owing to the exposure of the radiometer to low albedo surfaces directly below the instrument. As a result, the magnitude of $\Delta Q_{S}$ computed from observations (Eq. (3)) for this site is probably an overestimation for the neighbourhood; this partly explains the differences between observations and simulations. In this regard it is interesting to note the simulated values for $K \uparrow$ at the LCZ6 site is likely more realistic representation for the surrounding area than observed $K \uparrow$.

The Objective Hysteresis Model (Grimmond et al., 1991; Grimmond and Oke, 1999) (OHM) which is the sub model within SUEWS that directly relates to $\Delta Q_{S}$ in all modes overestimates storage relative to the observational data. It is also important to consider the energy balance closure problem (see for example: Kanda et al., 2004; Kawai and Kanda, 2010; Foken, 2008) which relates to the underestimation of the turbulent fluxes in observational data. The observational data here are corrected following Webb et al. (1980), which results in increasing $Q_{E}$ and decreasing $Q_{H}$ and somewhat reducing the residual. Nevertheless, as per (Eq. (3)) the likelihood is that $\Delta Q_{S}$ is exaggerated by the observational data. This especially important to highlight if examining the nocturnal withdrawal of heat from the substrate leading to (for instance) the UHI effect.

Overall the daily and hourly flux patterns simulated by SUEWS at both urban and suburban sites show good agreement with the observed fluxes. When provided with observed $K \downarrow$ and $L \downarrow$, SUEWS distinguishes between the two sites on the basis of the non-radiative terms: the model results under(over)-estimated $Q_{E}$ and over(under)-estimated $Q_{H}$ and $\Delta Q_{S}$ at the urban (suburban) site. The role of $Q_{E}$ appears to be critical as its magnitude is managed by the availability of water and plant growth. The former here is expressed in terms of the soil moisture content, which is set to field capacity. The latter is a function of the vegetative fraction and leaf area fraction. Looking at the daily and hourly simulations of SUEWS (Figs. 2 and Fig. 4) it seems that the description of plant growth (canopy cover, tree species, etc.) may be critical, which is consistent with Grimmond et al. (2011). In addition, the model has difficulty in responding quickly to precipitation events when rapid increases in the magnitude of $Q_{E}$ are observed.

\subsection{Impact of non-local meteorological and LCZ data}

Using off-site meteorological observations of $K \downarrow$ and of temperature and relative humidity to estimate $L \downarrow$ increases the difference between the observations at the site and SUEWS simulations but nevertheless the model still shows itself capable of discriminating between neighbourhood types. The use 
of LCZs to capture information about the type of neighbourhood in which the observation site is located has a marginal effect. The differences in meteorology between the off-site and on-site stations are highlighted in Tables 6 and 7. Such differences may be expected of most cities where off-site meteorological stations conforming to WMO standards will likely record higher wind speeds (due to less friction), colder air temperatures (more evapotranspiration, less heat storage) and higher levels of precipitation. This was not the case for Dublin, where off-site recordings were cooler, but wind speeds were also lower. In order to verify this finding, additional situations comparing off-site and on-site data with respect to model performance are needed; we plan to undertake this in a subsequent paper.

Nevertheless the differences between Modes were relatively minor, moreover the model showed itself to be relatively insensitive to such differences. This suggests that SUEWS may be used to discriminate between different urban neighbourhoods by sampling from within LCZs and obtaining land-cover fractions and forcing the model with off-site meteorology.

To test this proposition, we ran SUEWS in Mode 3 for four additional LCZ types present in the Dublin area to represent other urban and non-urban covers. These include: compact low-rise (LCZ3) for inner-city residential area; large low-rise (LCZ8) for warehouse areas found at the edge of the city; low plant cover (LCZ104) for grass-covered landscape and; closed trees (LCZ101) for forested areas. Each LCZ area was sampled (Table 5) as before and fractional areas were calculated. Fig. 5 shows the mean value for each non-radiative flux for June 2010 for each LCZ, including the urban and suburban LCZs used in the body of this study. The values are presented as a difference from the overall mean calculated for the six LCZs; thus, $Q_{H}$ for an LCZ is shown as the difference from the mean $Q_{H}$ value for all LCZ. This highlights the partitioning of the UEB across different LCZs. The results make intuitive sense. Note that the LCZs with the highest combined fractions of buildings and impervious surface cover (LCZs 2, 3 and 8) exhibit above average values of $Q_{H}$ and $\Delta Q_{S}$; these areas store more sensible heat (higher surface temperatures) and heat the overlying atmosphere rather than evaporate water. Oppositely, the well vegetated suburbs and the natural land-covers partition available energy into $Q_{E}$ rather than $Q_{H}+\Delta Q_{S}$.

Stewart and Oke (2012) speculate that energy partitioning zones are unlikely to coincide exactly with LCZs because similar flux densities can occur above canopy layers with distinctly different microscale structure, land cover, and thermal climate. The profiles for June presented in Fig. 5 illustrates this

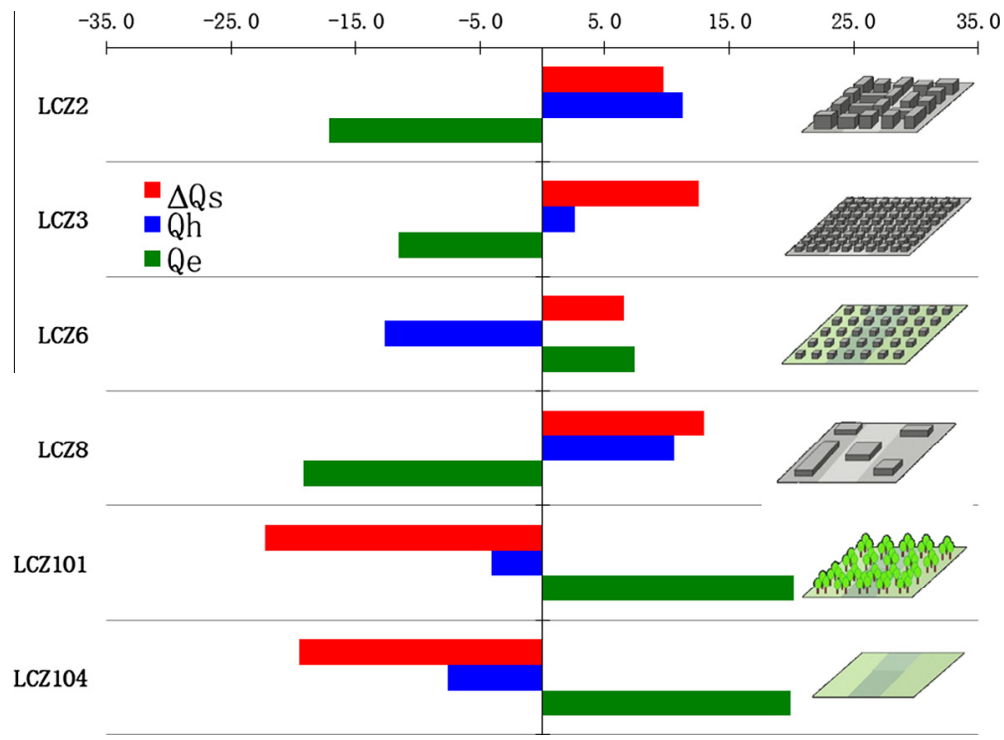

Fig. 5. Relative partitioning of turbulent fluxes at each LCZ site for June (2010) the mean value of $Q_{H}, Q_{E}$ and $\Delta Q_{S}$ for each LCZ are subtracted from the group mean. $X$-axis is $\mathrm{W} \mathrm{m}^{-2}$. LCZ images reproduced from Stewart and Oke (2012). 
problem, note for instance $Q_{H}$ profiles for LCZ2 and LCZ3 vary by $<10 \mathrm{~W} \mathrm{~m}^{-2}$ However, these data have been averaged in order to examine the signal for the entire month of June. Diurnal variations exhibited a higher degree of variation than the mean value for June; moreover energy partitioning for specific boundary layer conditions (for instance high pressure, little wind, no precipitation) maybe of greater importance to one user than other, reinforcing the earlier point on the need for models to undergo extensive validation in differing circumstances and conditions.

Nevertheless the LCZ classification provides a useful sampling framework for the derivation of the land-cover fractions needed to run SUEWS. This proved an efficient and effective means of gathering LCZ data here and provided a means of extending the model to other parts of the city. However, using the LCZ for this, does introduce a degree of subjectivity into data acquisition as there is no objective means of delineating a spatially contiguous LCZ type for individual cities. Ultimately users should avoid simply employing the mid-range of values which are provided for each LCZ type to derive land cover and/or anthropogenic parameters. For example within Dublin, the fractional coverage of buildings for LCZ2 was at the lowest end of the provided LCZ range, while impervious fraction was at the highest end of the range. Meaning the generic LCZ2 mid-range would not accurately describe this LCZ in Dublin.

While the scheme allows for sub-categories within each LCZ category, for example: dense compact midrise/open compact midrise etc. the development of mean values for the objective discrimination between LCZ types (rather than within a single LCZ class) would allow for a more consistent usage and allow comparisons between LCZs across cities and climate types.

\section{Summary and conclusion}

The input needs of urban atmospheric models present a barrier to their application in many places where information on the physical characteristics and urban energy budgets are sparse. Here we examined a means to overcome this obstacle by presenting a modelling framework that draws upon basic descriptions of the characteristics of city (Local Climate Zones) and tested this with a moderately complex urban energy budget model (SUEWS) which was forced with meteorological data obtained from outside the urban area. The use of forcing data obtained from a WMO synoptic station in lieu of data obtained from flux observation platforms in SUEWS resulted in a slight reduction in relative model performance against two urban types. The use of parameters that represent LCZ types however had no significant impact in this case study.

Our primary aim was to demonstrate/validate a modelling approach that could apply a moderately complex UEB model utilising readily available data beyond one or two instrumented sites. Based on the results from Dublin, SUEWS appears capable of being run with easily obtainable meteorological and land cover data with no significant impact on model performance across multiple seasons.

\section{Acknowledgments}

We wish to acknowledge the helpful comments of the anonymous reviewers. The authors also wish to acknowledge the kind advice of the SUEWS model developers while carrying out the model runs for all cases. The detailed land cover data for Dublin is provided by the OSI. The Flux sites are funded by the Higher Education Authority of Ireland. This work is funded by the Doctoral Teaching Fellowship, Maynooth University, supported through HEA Ireland.

\section{References}

Alexander, P.J., Mills, G., 2014. Local climate classification and Dublin's urban heat island. Atmosphere 5 (4), $755-777$.

Arnfield, J., 2003. Two decades of urban climate research: a review of turbulence, exchanges of energy and water, and the urban heat island. Int. J. Climatol. 23 (1), 1-26.

Bechtel, B., Alexander, P.J., Böhner, J., Ching, J., Conrad, O., Feddema, J., Mills, G., See, L., Stewart, I., 2015. Mapping local climate zones for a worldwide database of the form and function of cities. ISPORS Int. J. Geo-Inf. 4, 199-219.

Breuste, J., 2004. Decision making, planning and design for the conservation of indigenous vegetation within urban development. Landscape Urban Plan 68 (1), 439-452.

Chen, L., Ng, E., 2012. Outdoor thermal comfort and outdoor activities: a review of research in the past decade. Cities 29, 118125. 
Ching, J., 2013. A perspective on urban canopy layer modeling for weather, climate and air quality applications. Urban Climate 3 (1), 13-39.

Cleugh, H., Bui, E., Mitchell, V., Xu, J., Grimmond, C., Simon, D., 2005. Evapotranspiration in urban water balance models: a methodological framework. Canberra, Australia: International Congress on Modelling and Simulation (MODSIM05).

Fenner, D., Meier, F., Scherer, D., Polze, A., 2014. Spatial and temporal air temperature variability in Berlin, Germany, during the years 2001-2010. Urban Climate 10, 308-331.

Foken, T., 2008. The energy balance closure problem: an overview. Ecol. Appl. 18 (6), 1351-1367.

Griensven, A., Francos, A., Bauwens, W., 2002. Sensitivity analysis and auto-calibration of an integral dynamic model for river water quality. Water Sci. Technol. 45 (9), 325-332.

Grimmond, C., Oke, T., 1991. An evaporation-interception model for urban areas. Water Resour. Res. 27 (7), 1739-1755.

Grimmond, C., Oke, T., 1999. Heat storage in urban areas: local-scale observations and evaluation of a simple model. J. Appl. Meteorol. 38 (2), 922-940.

Grimmond, C., Oke, T., 2002. Turbulent heat fluxes in urban areas: observations and a local-scale urban meteorological parameterization scheme (LUMPS). J. Appl. Meteorol. 41 (7), 792-810.

Grimmond, C., Souch, C., 1994. Surface description for urban climate studies: a GIS based methodology. Geocarto Int. 1, 47-59.

Grimmond, C., Blackett, M., Best, M., Barlow, J., Baik, J., Belcher, S., et al, 2010. The international urban energy balance models comparison project: first results from phase 1. J. Appl. Meteorol. Climatol. 49, 1268-1292.

Grimmond, C., Blackett, M., Best, M., Barlow, J., Baik, J., Belcher, S., et al, 2011. Initial results from Phase 2 of the international urban energy balance model comparison. Int. J. Climatol. 31 (2), 244-272.

Grimmond, C., Cleugh, H., Oke, T., 1991. An objective urban heat storage model and its comparison with other schemes. Atmos. Environ. Part B. Urban Atmos. 25 (3), 311-326.

Hidalgo, J., Masson, V., Baklanov, A., Pigeon, G., Gimeno, L., 2008. Advances in urban climate modeling. Ann. N. Y. Acad. Sci. 1146, 354-374.

IPCC, 2014. Climate change 2014: impacts, adaptation, and vulnerability. Part A: Global and sectoral aspects. In: Field, C.B., Barros, V.R., Dokken, D.J., Mach, K.J., Mastrandrea, M.D., Bilir, T.E., Chatterjee, M., Ebi, K.L., Estrada, Y.O., Genova, R.C., Girma, B., Kissel, E.S., Levy, A.N., MacCracken, S., Mastrandrea, P.R., White, L.L. (Eds.), Contribution of Working Group II to the Fifth Assessment Report of the Intergovernmental Panel on Climate Change. Cambridge University Press, Cambridge, United Kingdom and New York, NY, USA, p. 1132.

Järvi, L., Grimmond, C., Christen, A., 2011. The surface urban energy and water balance scheme (SUEWS): evaluation in Los Angeles and Vancouver. J. Hydrol. 411 (3-4), 219-237.

Kanda, M., Inagaki, A., Letzel, M.O., Raasch, S., Watanabe, T., 2004. LES study of the energy imbalance problem with eddy covariance fluxes. Bound.-Layer Meteorol. 110, 381-404.

Kanda, M., Kawai, T., Kanega, M., Moriwaki, R., Narita, K., Hagishima, A., 2005. Simple energy balance model for regular building arrays. Bound.-Layer Meteorol. 116, 423-443.

Kawai, T., Kanda, M., 2010. Urban energy balance obtained from the comprehensive outdoor scale model experiment. Part I: Basic features of the surface energy balance. J. Appl. Meteorol. Climatol. 49, 1360-1376.

Keogh, S., Fealy, R., Mills, G., 2012. The energy budget of the urban surface: two locations in Dublin. Irish Geogr. 45 (1), 1-23.

Kimura, F., Takahashi, S., 1991. The effects of land-use and anthropogenic heating on the surface temperature in the Tokyo metropolitan area: a numerical experiment. Atmos. Environ. 25B, 155-164.

Kovács, A., Németh, Á., 2012. Tendencis and differences in human thermal comfort in distinct urban areas in Budapest, Hungary. Acta Climatologica et Chorologica 46, 115-124.

Kusaka, H., Kimura, F., 2004. Thermal effects of urban canyon structure on the nocturnal heat island: numerical experiment using a mesoscale model coupled with an urban canopy model. J. Am. Meteorol. Soc. 43, 1899-1910.

Leconte, F., Bouyer, J., Claverie, R., Pétrissans, M., 2014. Using local climate zone scheme for UHI assessment: evaluation of the method using mobile measurements. Build. Environ.

Loridan, T., Grimmond, C., 2012. Multi-site evaluation of an urban land-surface model: intra-urban heterogeneity, seasonality and parameter complexity requirements. Quart. J. Roy. Meteorol. Soc. 138 (665), 1094-1113.

Loridan, T., Grimmond, C., Grossman-Clarke, S., Chen, F., Tewari, M., Manning, K., et al, 2010. Trade-offs and responsiveness of the single-layer urban canopy parameterization in WRF: an offline evaluation using the MOSCEM optimization algorithm and field observations. J. Roy. Meteorol. Soc. 136, 997-1019.

Loridan, T., Grimmond, C., Offerle, B., Young, D., Smith, T., Järvi, L., et al, 2011. Local-scale urban meteorological parameterization scheme (LUMPS): longwave radiation parameterization and seasonality-related developments. J. Appl. Meteorol. Climatol. 50 (1), 185-202.

Martilli, A., Clappier, A., Rotach, M., 2002. An urban surface exchange parameterisation for mesoscale models. Bound.-Layer Meteorol. 104, 261-304.

Masson, V., 2000. A physically-based scheme for the urban energy budget in atmospheric models. Bound.-Layer Meteorol. 94, $357-397$.

Middel, A., Brazel, A., Kaplan, S., Myint, S., 2012. Daytime cooling efficiency and diurnal energy balance in Phoenix, Arizona, USA. Climate Res. 54, 21-34.

Mills, G., 1997. An urban canopy-layer climate model. Theoret. Appl. Climatol. 57, 229-244.

Moonen, P., Defraeyne, T., Doresr, V., Blocken, B., Carmeliet, J., 2012. Urban physics: effect of micro-climate on comfort, health and energy demand. J. Front. Archit. Res. 1 (3), 197-228.

Ningal, T., Mills, G., Smithwick, P., 2010. An inventory of trees in Dublin city centre. Irish Geogr. 43 (2), 161-176.

Oke, T., 1980. Climatic impacts of urbanization. In: Bach, W., Pankrath, J., Williams, J., (Eds.), Interactions of Energy and Climate. Proceedings of International Workshop on Energy and Climate, Münster, Germany, Germany, pp. 339-361.

Oke, T., 1988. The urban energy balance. Prog. Phys. Geogr. 12 (4), 471-508.

Oke, T., 2006. Towards better scientific communication in urban climate. Theor. Appl. Climatol. 84, 179-190.

Pigeon, G., Legain, D., Durand, P., Masson, V., 2007. Anthropogenic heat release in an old European agglomeration (Toulouse, France). Int. J. Climatol. 27 (14), 1969-1981. 
Satterthwaite, D., 2007. Climate change and urbanization: effects and implications for urban governance. United Nations Expert Group on Population Distribution, Urbanization, Internal Migration and Development, New York.

Schuster, W., Bonta, J., Thurston, H., Warnemuende, E., Smith, D., 2005. Impacts of impervious surface on watershed hydrology: a review. Urban Water J. 2 (4), 263-275.

Schwela, D., 2000. Air pollution and health in urban areas. Rev. Environ. Health 15 (1), 13-42.

Stewart, I., Oke, T., 2012. Local climate zones for urban temperature studies. Bull. Am. Meteorol. Soc. 93, 1879-1900.

Stewart, I.D., Oke, T.R., Krayenhoff, E.S., 2014. Evaluation of the "local climate zone" scheme using temperature observations and model simulations. Int. J. Climatol. 34, 1062-1080.

Taha, H., 1999. Modifying a mesoscale meteorological model to better incorporate urban heat storage: a bulk-parameterization approach. J. Appl. Meteorol. 38, 466-473.

Taylor, K.E., 2001. Summarizing multiple aspects of model performance in a single diagram. J. Geophys. Res. 106 (D7), 71837192. http://dx.doi.org/10.1029/2000JD900719.

UN, 2012. United Nations Department of Economic and Social Affairs (DESA) Population Division: World Urbanization Prospects, the 2011 Revision. Final Report with Annex Tables, New York.

Webb, E.K., Pearman, G.I., Leuning, R., 1980. Correction of flux measurements for density effects due to heat and water vapour transfer. Q.J.R. Meteorol. Soc. 106, 85-100. http://dx.doi.org/10.1002/qj.49710644707. 